\title{
Supporting information Into deep water: optimising BCL6 inhibitors by growing into a solvated pocket
}

Matthew G. Lloyd‡, Rosemary Huckvale‡, Kwai-Ming J. Cheung, Matthew J. Rodrigues, Gavin W. Collie* ${ }^{*}$ Olivier A. Pierrat, Mahad Gatti Iou, Michael Carter, Owen A. Davis, P. Craig McAndrew, Emma Gunnell, Yann-Vaï Le Bihan, Rachel Talbot, Alan T. Henley, Louise D. Johnson, Angela Hayes, Michael D. Bright, Florence I. Raynaud, Mirco Meniconi, Rosemary

Burke, Rob L. M. van Montfort ${ }^{\#}$, Olivia W. Rossanese, Benjamin R. Bellenie ${ }^{\dagger *}$, Swen Hoeldert*

\begin{abstract}
AUTHOR ADDRESS
${ }^{\dagger}$ Cancer Research UK Cancer Therapeutics Unit and \#Division of Structural Biology, The Institute of Cancer Research, London SM2 5NG, U.K.
\end{abstract}

*E-mail: Benjamin.Bellenie@ @icr.ac.uk. Phone: +44 (0) 2087224602 (B.B.).

*E-mail: Swen.Hoelder@icr.ac.uk. Phone: +44 (0) 2087224353 (S.H.). 
Contents

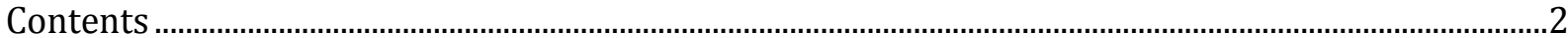

1. Supplementary experimental: protein production, purification and crystallography........3

1.1 BCL6 constructs used for assays and crystallography ….........................................................

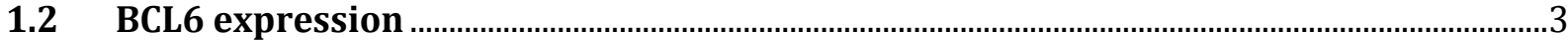

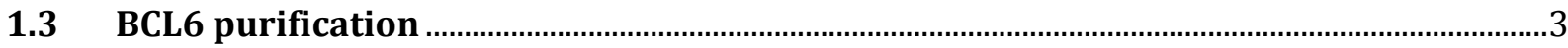

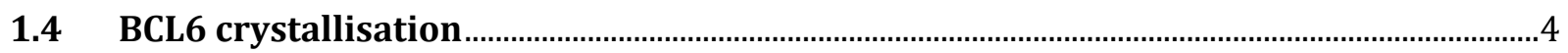

1.5 Crystallographic data collection, processing and refinement …..........................................

2. Supplementary experimental: biological assay conditions .......................................................6

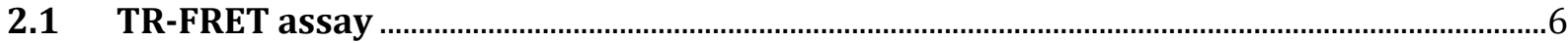

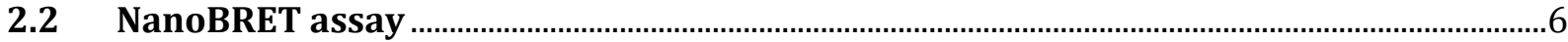

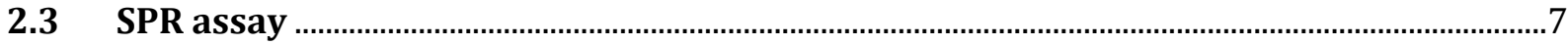

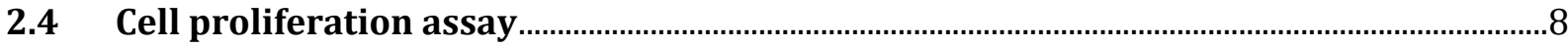

3. Supplementary experimental: physicochemical assays ….......................................................

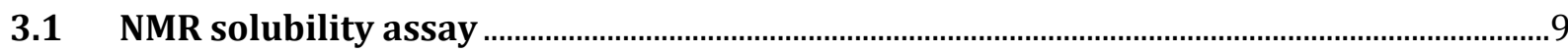

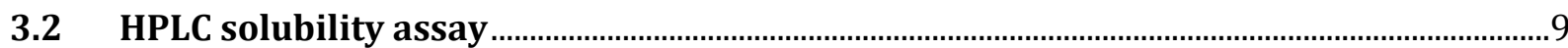

4. Supplementary experimental: in silico experiments...............................................................11

4.1 Analysis of thermodynamic properties of water molecules using Openeye SZMAP..11

5. Supplementary experimental: in vivo PK and PD experiments................................................12

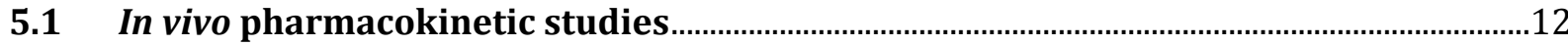

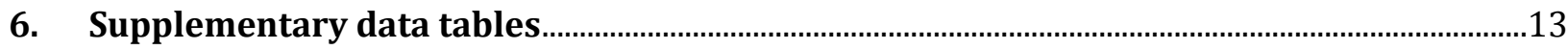

Supplementary Table S1: Crystallographic data collection and refinement statistics. .........................13

Supplementary Table S2: Individual values and summary statistics for TR-FRET assay. ....................17

Supplementary Table S3: Individual values and summary statistics for NanoBRET assay. .................18

Supplementary Table S4: SPR sensorgrams and Langmuir curves ............................................................18

Supplementary Table S5: Data (individual replicates) from pharmacokinetic study of 25. ................19

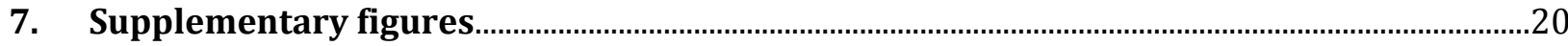

Supplementary Figure S1: Alternative binding conformations of 8 e shown by $X$-ray ..........................20

Supplementary Figure S2: X-ray structure of $12 \boldsymbol{e}$ bound to the BTB domain of BCL6.........................20

Supplementary Figure S3: Alternative view of X-ray structures of $8 \boldsymbol{f}$ showing key measurements....21

Supplementary Figure S4: Concentration:time curves from PK study with 25 ....................................24

Supplementary Figure S5: Curves from 14-day cell viability assays with compound 25 .....................25

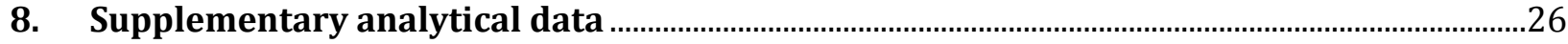

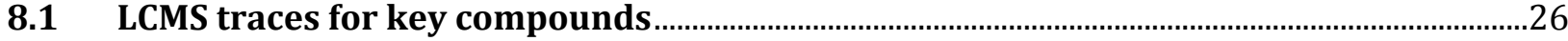

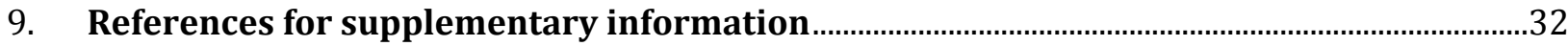




\section{Supplementary experimental: protein production, purification and crystallography}

\subsection{BCL6 constructs used for assays and crystallography}

A first construct of BCL6 BTB domain, which we will refer to as Trx-6His-HRV3C-BCL6, was obtained by sub-cloning the sequence coding for residues 5-129 of human BCL6, corresponding to its BTB domain, into a pET48b vector with N-terminal Thioredoxin and 6-Histidine tags, followed by a HRV3C protease cleavage site. For the TR-FRET assay, the Trx-6His-HRV3C-BCL6 protein construct was used without cleaving the tag, as a 6His was needed to bind to the anti-6His-Terbium antibody. For the FP assay and crystallography with compounds 2, 8c, 8e, 8f, 12b, 12c, 12e, 13e and 13g, the tag was removed by HRV-3C protease treatment, generating a simpler BCL6 5-129 product.

For crystallography with compound 25 , the construct described above was modified to introduce a Flag Tag and a TEV cleavage site between the HRV3C and BCL6 sequences. This construct will be referred to as Flag-TEV-BCL6.

\subsection{BCL6 expression}

For both plasmid constructs described above, transformed BL21-AI E. coli cells were grown in LB media supplemented with $50 \mathrm{mg} / \mathrm{L}$ kanamycin at $37^{\circ} \mathrm{C}$ until an OD600 $\mathrm{nm}$ of 0.6 was reached. Protein expression was then induced by addition of $0.2 \mathrm{mM}$ IPTG and $0.2 \%$ Arabinose. Expression was carried out at $18{ }^{\circ} \mathrm{C}$ for 18 hours. Cells were harvested by centrifugation (5500 g for 30 minutes at 4 ${ }^{\circ} \mathrm{C}$ ) and stored at $-80{ }^{\circ} \mathrm{C}$.

\subsection{BCL6 purification}

Cells were re-suspended in a buffer composed of $20 \mathrm{mM}$ Tris pH 8, $250 \mathrm{mM} \mathrm{NaCl}, 1 \mathrm{mM} \mathrm{MgCl} 2,0.5$ mM TCEP and $5 \%$ glycerol, $1 \mathrm{x}$ cOmplete ${ }^{\mathrm{TM}}$ ULTRA protease inhibitors and $12.5 \mathrm{U} / \mathrm{ml}$ Benzonaze. Cells were lysed by sonication followed by centrifugation at $21,000 \mathrm{~g}$ for 45 minutes at $4{ }^{\circ} \mathrm{C}$. The supernatant was loaded onto a HisTrap FF column followed by on-column cleavage of the Trx-6HisHRV3C tag by addition of $2 \mathrm{mg}$ of HRV-3C protease. The cleaved BCL6 5-129 BTB domain or FlagTEV-BCL6 5-129 was then eluted and purified further by ResourceQ (for Flag-TEV-BCL6 construct only) and gel filtration using a HiLoad 26/60 Superdex75 column in a buffer containing $20 \mathrm{mM}$ HEPES pH 7.5, $250 \mathrm{mM} \mathrm{NaCl}, 1 \mathrm{mM}$ TCEP and 5 \% glycerol. The final protein was assessed for purity and molar mass by SDS-PAGE and high-resolution mass spectrometry, respectively. 
For the uncleaved Trx-6His-HRV3C-BCL6 protein construct to be used in TR-FRET, the protein was directly eluted from the HisTrap FF column without HRV-3C treatment, and submitted to Superdex75 gel filtration as described above.

\subsection{BCL6 crystallisation}

The purified BCL6 5-129 was crystallised in the presence of a tetra-peptide of sequence Ac-WVIP$\mathrm{NH}_{2}$. A stock solution of WVIP peptide at $100 \mathrm{mM}$ in $100 \%$ DMSO was added to a $2 \mathrm{mg} / \mathrm{mL}$ solution of purified BCL6 to a final concentration of $1 \mathrm{mM}$. This mixture was then concentrated to a final protein concentration of $4 \mathrm{mg} / \mathrm{mL}$ using a centrifugal concentrator with a $3 \mathrm{kDa}$ molecular weight cut-off. Crystals were grown at $18{ }^{\circ} \mathrm{C}$ in hanging drops composed of $2 \mu \mathrm{L}$ of the BCL6-BTB/WVIP complex plus $1 \mu \mathrm{L}$ of a crystallisation solution consisting of $1 \mathrm{M} \mathrm{K}_{2} \mathrm{HPO}_{4}, 0.7 \mathrm{M} \mathrm{NaH}_{2} \mathrm{PO}_{4}, 75 \mathrm{mM}$ sodium acetate buffer $\mathrm{pH} 4.5$ and $2 \%$ DMSO, against $350 \mu \mathrm{L}$ of crystallisation solution. Crystals typically grew in 2 days, and compounds were soaked into crystals by addition of $0.5 \mu \mathrm{L}$ of each compound (dissolved in DMSO to a final concentration of 10 to $200 \mathrm{mM}$ ) directly to crystallisation drops, followed by 10-120 minutes incubation. Crystals were then cryo-protected in a solution composed of the crystallisation reagent supplemented with $30 \%$ ethylene glycol and cryo-cooled in liquid nitrogen.

The purified Flag-TEV-BCL6 5-129 was crystallised without any peptide, the supplementary FlagTEV tag of this construct replacing the WVIP peptide in the crystal packing. The protein was concentrated to a final protein concentration of $10 \mathrm{mg} / \mathrm{mL}$ using a centrifugal concentrator with a 3 $\mathrm{kDa}$ molecular weight cut-off. Crystals were grown at $18{ }^{\circ} \mathrm{C}$ in hanging drops composed of $1.5 \mu \mathrm{L}$ of the Flag-TEV-BCL6 complex plus $1.5 \mu \mathrm{L}$ of a crystallisation solution consisting of $0.1 \mathrm{M}$ Tris pH 7.5 and $0.80 \mathrm{M} \mathrm{Na} / \mathrm{K}$ Tartrate, against $300 \mu \mathrm{L}$ of crystallisation solution. Crystals typically grew in 2 days, and compounds were soaked as described above for the other construct. Crystals were then cryoprotected in a solution composed of the crystallisation reagent supplemented with $30 \%$ ethylene glycol and cryo-cooled in liquid nitrogen.

\subsection{Crystallographic data collection, processing and refinement}

X-ray data were collected at Diamond Light Source, Harwell campus, Oxfordshire, UK, on beamlines I03, and I04-1, at ESRF, Grenoble, France, on beamline ID30A-1, or in-house at the Institute of Cancer Research, London, UK, on a Rigaku FRX-AFC11-VariMax Cu-VHF-Pilatus300K. Crystals obtained with both BCL6 constructs belonged to the space group P $6{ }_{1} 22$ and diffracted to between 1.25 and 2.05 
Å resolution. Datasets were integrated with $\mathrm{XDS}^{1}$ or DIALS ${ }^{2}$ and scaled and merged with AIMLESS ${ }^{3}$ or AutoPROC. ${ }^{4}$ Structures were solved by molecular replacement using PHASER $^{5-6}$ with a publicly available BCL6 structure ${ }^{7}$ (PDB code 3BIM) with ligand and water molecules removed used as molecular replacement model. All protein/ligand structures were manually corrected and rebuilt in $\mathrm{COOT}^{8}$ and refined with BUSTER ${ }^{9}$ in iterative cycles. Ligand restraints were generated with GRADE ${ }^{10}$ and MOGUL ${ }^{11}$. The quality of the structures was assessed with MOLPROBITY12-13. The data collection and refinement statistics are presented in Supplementary Table S1. 


\section{Supplementary experimental: biological assay conditions}

Cell lines were supplied by the German Collection of Microorganisms and Cell Cultures (DSMZ). Cell lines were authenticated by STR profiling using a GenePrint ${ }^{\circledR} 10$ kit (Promega, Southampton, UK) and a 3730xl DNA analyser (Applied Biosystems, Warrington, UK). All STR profiles were $>80 \%$ match (using ATCC or DSMZ matching algorithms) with the respective reference profile. Cells were routinely screened for Mycoplasma, using an in-house PCR-based assay (Universal Mycoplasma Detection Kit (30-1012K, ATCC, Manassas, VA, USA).

\subsection{TR-FRET assay}

Assays were performed in a 384-well black Proxiplate (Perkin Elmer) containing 1 nM* Trx-6xHisBCL6 (in house-produced, human BCL6 BTB domain covering amino-acid sequence 5-129), $300 \mathrm{nM}$ BCOR-AF633 peptide (RSEIISTAPSSWVVPGP-Cys-AlexaFluor 633-amide, Cambridge Research Biochemical) and $0.5 \mathrm{nM}$ anti-6xHis-Terbium cryptate (CisBio Bioassays, France), in assay buffer (25 mM Hepes pH8, $100 \mathrm{mM} \mathrm{NaCl}$, 0.05\% Tween20, $0.5 \mathrm{mM}$ TCEP, 0.05\% bovine serum albumin). Test compounds in DMSO or DMSO alone were added to the wells using an ECHO550 acoustic dispenser (Labcyte Inc) to give the appropriate test concentration in $0.7 \% \mathrm{v} / \mathrm{v}$ DMSO final. After 2 hours incubation at room temperature the plate was read on an Envision plate reader (Perkin Elmer) with $337 \mathrm{~nm}$ laser excitation, a first emission filter APC $665 \mathrm{~nm}$ and a second emission filter Europium $615 \mathrm{~nm}$, or alternatively on a Pherastar FSX (BMG Labtech) plate reader equipped with $337 \mathrm{~nm}$ laser excitation filter, a first emission filter at $620 \mathrm{~nm}$ and a second emission filter at $665 \mathrm{~nm}$. The \% inhibition at each concentration was calculated by normalising FRET ratio to the appropriate high (DMSO with all reagents) and low (DMSO without BCL6) controls. IC $_{50}$ values were determined using GraphPad Prism 6.0 or Dotmatics (Bishops Stortford, UK) software by fitting the normalised data to a sigmoidal four-parameter logistic fit equation.

*10 nM was used for early examples, as indicated in data tables.

\subsection{NanoBRET assay}

A cellular nano-Bioluminescence Resonance Energy Transfer (nanoBRET) assay (Promega NanoBRET Nano-Glo Detection System, catalogue number N1662) was used to detect inhibition of the BCL6-SMRT (also called NCOR2) corepressor protein-protein interaction. DNA encoding full length BCL6 and SMRT were inserted into pFC32K.NanoLuc and pFC14K.HaloTag vectors (Promega) to produce C-terminal tagged fusion proteins BCL6-nanoLuc and SMRT-HaloTag, respectively. 
HEK293T cells were plated $\left(5 \times 10^{5}\right)$ in T75 tissue culture flask and bulk transfected 48 hours later with Fugene 6 (Promega cat.\# E2691) reagent and $18 \mu$ g total DNA plasmids encoding BCL6-nanoLuc as donor and SMRT-HaloTag as acceptor, at a donor:acceptor DNA ratio of 1:25. At $24 \mathrm{hr}$ posttransfection, HEK293T cells were collected and stored in liquid nitrogen in 90\% FBS (PAN Biotech UK) and 10\% DMSO. At the time of assay, compounds (100nL/well) and NanoBRET 618 ligand (10nL of $1 \mathrm{mg} / \mathrm{ml}$ stock solution per well) were dispensed in a dry 384-well NUNC white assay plate (ThermoScientific NUNC cat.\#10080681) using Echo550 acoustic dispensing (Labcyte Inc.). Frozen transfected HEK293T cells were thawed, centrifuged and freezing medium was replaced by phenol red-free OptiMEM+4\% FBS (Life Technology). The cell density was adjusted to $3 \times 10^{5}$ cells $/ \mathrm{ml}$ and $20 \mu \mathrm{L}$ (6000 cells) were plated in each well containing test compounds (0.0125-50 $\mu \mathrm{M})$ in DMSO or DMSO alone and $0.5 \mu \mathrm{g} / \mathrm{ml}$ NanoBRET 618 fluorescence ligand, in 0.55\% v/v DMSO final concentration. Cells were incubated for $6 \mathrm{hr}$ at $37^{\circ} \mathrm{C} / 5 \% \mathrm{CO}_{2}$ then NanoBRET furimazine substrate (Promega) was added to give a final concentration of $10 \mu \mathrm{M}$. After a short centrifugation the plates were read on an Envision (Perkin Elmer) plate reader equipped with a LUM/D600 Dual mirror, Lum 450/40 $\mathrm{nm}$ bandpass and D605 nm longpass filters, with a $0.2 \mathrm{sec}$ reading to determine the BRET ratio. Alternatively, plates were read on Pherastar FSX (BMG Labtech) equipped with BRET module LP610 nm ( $1^{\text {st }}$ emission filter $) / 450-80 \mathrm{~nm}$ ( $2^{\text {nd }}$ emission filter). The \% inhibition at each test concentration was calculated by normalising the BRET ratio to the appropriate high and low controls. The compound $\mathrm{IC}_{50}$ s were determined using Graphpad Prism 6.0 or Dotmatics software by fitting the normalised data to a sigmoidal four-parameter logistic fit equation.

\subsection{SPR assay}

Surface plasmon resonance (SPR) experiments were carried out on a Biacore T200 (GE Healthcare Life Sciences) and amine coupling chemistry was used to immobilise the protein on a research grade CM5 sensor chip. The running buffer was $100 \mathrm{mM}$ sodium acetate, $100 \mathrm{mM}$ sodium chloride, $1 \mathrm{mM}$ TCEP pH6.0 and the chip's surface was activated for $10 \mathrm{~min}$ using a $1: 1$ mixture of $100 \mathrm{mM} \mathrm{N}$ hydroxysuccinimide and 400mM 1-ethyl-3-(3-dimethylaminopropyl)-carbodiimide. BCL6 BTB protein was injected for $20 \mathrm{~min}$ at a concentration of $100 \mu \mathrm{g} / \mathrm{mL}$ in a $10 \mathrm{mM}$ sodium acetate buffer

pH5.5. Finally, the surface was blocked via an injection of $1 \mathrm{M}$ ethanolamine pH8.5 for $7 \mathrm{~min}$. The flow rate was maintained at $10 \mu \mathrm{L} / \mathrm{min}$ for all the above procedures and $\sim 1500$ response units (RU) of BCL6 was immobilised on the chip. Flow cell one was left unmodified as the reference surface. 
Following protein immobilisation, the running buffer was changed to $100 \mathrm{mM}$ sodium acetate, 100mM sodium chloride, 1mM TCEP, 0.05\% Tween20 (v/v), 5\% DMSO pH6.0.

All compound handling was done on an ECHO 550 acoustic liquid dispenser (Labcyte) and compounds were added to 384-well polypropylene V-bottomed plates (Greiner), which became the sample plates for the SPR. For KD determinations, an eight-point concentration range was generated as shown, with a final DMSO concentration of $4 \%$. The flow rate was $30 \mu \mathrm{L} / \mathrm{min}$, the injection time for the samples was 60 secs and the dissociation time was $60 \mathrm{sec}$. The surface was not regenerated between sample injections. KD values were calculated from the Langmuir plot under equilibrium conditions using the 1:1 binding model in the Biacore software version 2 (GE Life Sciences, Amersham Place, UK).

\subsection{Cell proliferation assay}

Cells were seeded in 96-well culture plates at a density of 2500 cells/well in RPMI-1640 medium (Sigma-Aldrich) supplemented with 10\% FBS (Gibco). Compounds were initially dispensed into 96well U-bottom plates using an Echo 550 acoustic dispenser (Labcyte Inc.), then diluted in RPMI-1640 medium and transferred onto the cells. Cells were treated with 8 compound concentrations in duplicate, ranging from $1.07 \mathrm{nM}$ to $10 \mu \mathrm{M}$, in a final DMSO concentration of $0.1 \%$ and final volume of $100 \mu \mathrm{l}$. Cells were incubated with compound for 14 days, with medium changes at days 3, 7 and 10 carried out as follows: fresh 96-well cell culture plates were prepared containing $100 \mu \mathrm{l}$ medium plus compound at the assay concentrations (white plates were used on day 10 to optimise luminescence measurement). Assay plates containing cells were vortexed to mix and cell density in one control well was counted using a Coulter Z2 cell counter (Beckman Coulter). The volume of medium containing 2500 cells in the control well was calculated and this volume of cells was transferred from every well of the assay plates to the corresponding well of the fresh plates containing compound. After 14 days, CellTiter Glo reagent (Promega) was added to the medium in each well of the assay plate at a ratio of $1: 2$, mixed on a plate shaker, then incubated at room temperature for 10 minutes. Luminescence was measured using an Envision plate reader (Perkin Elmer) and the relative luminescence at each compound concentration, compared to DMSO alone, was calculated. GI50 were determined using a 4-parameter curve fit in Dotmatics (Bishops Stortford, UK). 


\section{Supplementary experimental: physicochemical assays}

\subsection{NMR solubility assay}

$9 \mu \mathrm{L}$ of $10 \mathrm{mM}$ DMSO stock solution was pipetted into one well of a 384 deepwell plate (Greiner, partno. 781270), then $171 \mu \mathrm{L}$ of HEPES buffer (20 mM HEPES [Sigma Aldrich, cat-no. H3375-250G], 150 $\mathrm{mM} \mathrm{NaCl}, 0.5 \mathrm{mM}$ TCEP, $10 \% \mathrm{D}_{2} \mathrm{O}$ ) was pipetted into the same well and mixed by up-down pipetting 3 times to create a $0.5 \mathrm{mM}$ solution or suspension containing 5\% DMSO. It was then separated by centrifugation (1000 rpm for $1 \mathrm{~min}$, Eppendorf 5810C). The plate was then sealed and incubated at room temperature for 20 hours, without shaking. The plate was centrifuged again for 1 minute at $1000 \mathrm{rpm}$ on Eppendorf 5810R before $165 \mu \mathrm{L}$ of the supernatant was transferred to a $3 \mathrm{~mm}$ NMR tube (Bruker, Part No. Z112272) using liquid handler SamplePro Tube SJ S (Bruker). The concentration of the solubilized compound in solubility sample is measured by quantitative ${ }^{1} \mathrm{H}-\mathrm{NMR}$ using a single external standard (200 $\mu \mathrm{M}$ caffeine (Sigma, C1778) in PBS (pH 7.4) with 1\% DMSOd6).

The detail of the NMR method is as following: NMR data was collected on a Bruker Avance Neo 600 spectrometer equipped with a $5 \mathrm{~mm}$ TCI-CryoProbe. The ${ }^{1} \mathrm{H}$ spectrum was referenced to the internal deuterated solvent. The operating frequency for ${ }^{1} \mathrm{H}$ was $600 \mathrm{MHz}$. All NMR data were acquired at the temperature of $298 \mathrm{~K}$. All data were acquired and processed using Bruker Topspin 4.0. The quantitative ${ }^{1} \mathrm{H}-\mathrm{NMR}$ spectrum was acquired using a Bruker standard 1D lc1pngppsf2 pulse sequence with 32 scans. The sweep width was $6.2 \mathrm{ppm}$ with 01P set to $8.8 \mathrm{ppm}$, and the FID contained 16k time-domain data points. Relaxation delay was set to $20 \mathrm{sec}$. Water signal was suppressed. ${ }^{14-16}$

\subsection{HPLC solubility assay}

$10 \mu \mathrm{L}$ of $10 \mathrm{mM}$ DMSO stock solution was pipetted into a micro centrifuge tube $(1.5 \mathrm{~mL}$, Sarstedt part-no. 72.690.001) containing $990 \mu \mathrm{L}$ of PBS buffer (pH 7.4, Sigma Aldrich, cat-no. 79382) and mixed for 5 seconds on vortex mixer (Grant-bio vortex mixer) to create $100 \mu \mathrm{M}$ solution with $1 \%$ DMSO. Following shaking of the suspension on a Bohdan Shaker at $500 \mathrm{rpm}$ for 2 hours at room temperature $\left(20^{\circ} \mathrm{C}\right)$, it was separated by centrifugation (14000 rpm for $15 \mathrm{~min}$, Eppendorf $5415 \mathrm{C}$ ). $200 \mu \mathrm{L}$ of the supernatant was transferred to a $2 \mathrm{~mL}$ Agilent vial containing $50 \mu \mathrm{L}$ of DMSO (Sigma Aldrich, cat-no. 41640-100ML) and mixed for 5 seconds to avoid precipitation from the saturated solution. 
The concentration of the solubilized compound in solubility sample is measured by HPLC with UV detection using an external standard which was prepared by pipetting $10 \mu \mathrm{L}$ of the same batch of compound DMSO stock used in solubility sample preparation to $990 \mu \mathrm{L}$ of DMSO.

The detail of the HPLC method is as following: chromatographic separation at $30^{\circ} \mathrm{C}$ is carried out over a 5 minute gradient elution method from 90:10 to 10:90 water:methanol (both modified with $0.1 \%$ formic acid) at a flow rate of $1.5 \mathrm{~mL} / \mathrm{min}$. Calibration curve is prepared by injecting $0.5,2.5$, and $5 \mu \mathrm{L}$ of compound external standard. Compound solubility value is obtained by injecting 6.25 and $62.5 \mu \mathrm{L}$ of compound solubility sample. 


\section{Supplementary experimental: in silico experiments}

\subsection{Analysis of thermodynamic properties of water molecules using Openeye SZMAP.}

\section{Analysis of thermodynamic properties of water molecules using Openeye SZMAP.}

In the work described in this manuscript, we have used the Openeye SZMAP software [1] to analyze thermodynamic properties of water molecules in the binding site of BCL6, in the presence of several ligands, and to assess how different ligands can increase biological activity by favourably perturbating the water network around them. In particular, we used SZMAP to estimate the change in the relative free energy (called SZMAP neutral probe free energy difference, or simply $\Delta \Delta G$ ) when a water molecule observed in a crystal structure is replaced, computationally, by a hydrophobic probe. A positive $\Delta \Delta \mathrm{G}$ calculated at the coordinate of a particular water molecule indicates that a hydrophobic probe would be better tolerated in that position. On the contrary, a negative $\Delta \Delta \mathrm{G}$ indicates that the water molecule is sitting in a hydrophilic spot. Calculated $\Delta \Delta G$ values in the region of -0.5 to $+0.5 \mathrm{kcal} / \mathrm{mol}$ reflect a preference for neither polar nor hydrophobic probes. Work published in 2015 by Astra-Zeneca shows that the SZMAP calculated thermodynamic parameter correlates well with analogue results from more sophisticated computational methods as well as experimental data [2].

We carried out SZMAP water analyses on several BCL6:ligand complexes of interest, described in the results section. The PDB structures of the BCL6:ligand complexes used in our calculations were resolved in house. Hydrogen atoms positions and protonation states were then determined using the protonate-3D procedure implemented in MOE v2019 [3,4] using the default options and the GB/VI electrostatics. To estimate the $\Delta \Delta \mathrm{G}$ we used SZMAP v1.2.1.4 with all the default options. All the calculated $\Delta \Delta \mathrm{G}$ are provided as $\mathrm{kcal} / \mathrm{mol}$.

1. SZMAP; OpenEye Scientific Software Inc., Santa Fe, NM, USA, 2011

2. Bayden, A. S.; Moustakas, D. T.; Joseph-McCarthy, D.; Lamb, M. L. Evaluating Free Energies of Binding and Conservation of Crystallographic Waters Using SZMAP. Journal of chemical information and modeling 2015, 55 (8), 1552-1565. https://doi.org/10.1021/ci500746d.

3. Molecular Operating Environment (MOE), 2019.01; Chemical Computing Group ULC, 1010 Sherbooke St. West, Suite \#910, Montreal, QC, Canada, H3A 2R7, 2021.

4. Labute, P. Protonate3D: Assignment of ionization states and hydrogen coordinates to macromolecular structures. Proteins: Structure, Function, and Bioinformatics 2009, $75 \quad$ (1), 187-205. https://doi.org/10.1002/prot.22234. 


\section{Supplementary experimental: in vivo PK and PD experiments}

All procedures were in accordance with UK Home Office regulations under the Animals (Scientific Procedures) Act 1986, approved by The Institute of Cancer Research's Ethics Committee and in accordance with published guidelines ${ }^{17}$. Mice were allowed access to food and water ad libitum.

\subsection{In vivo pharmacokinetic studies}

All experiments were conducted in accordance with the UKCC guidelines for animal experimentations ${ }^{17}$. Animals were adapted to laboratory conditions for at least 1 week prior to dosing and were allowed food and water ad libitum. CCT369347 (25) was administered iv or po (mouse, $0.1 \mathrm{~mL} / 10 \mathrm{~g}$ in 10\% DMSO, 5\% tween 20 in saline); Blood samples were collected in heparinised capillaries from the tail vein at 8 time points over the $24 \mathrm{~h}$ post dose and frozen on collection together with a standard curve and quality controls spiked in control blood. Samples were reconstituted in a Water: $\mathrm{MeOH}$ mixture containing internal standard as previously described (Roberts et al, 2016). Following centrifugation, extracts were analyzed by multiple reaction monitoring of precursor and product ions by ESI-LCMS/MS on either a Waters (Milford, MA, USA) Xevo TQ-S or Sciex (Framingham, MA, USA) QTrap6500 following gradient separation with 0.1\% formic acid and methanol on a Phenomenex (Macclesfield, UK) Kinetex C18 UPLC column (50 × 2.1 $\mathrm{mm}, 2.6 \mu \mathrm{M})$. Quantitation was carried out with an external calibration. Quality controls were included and were within $20 \%$ of nominal concentration. Pharmacokinetic parameters were derived from noncompartmental analysis using Phoenix Pharsight. Non compartmental analysis (model 200 and 201) version 6.3. 


\section{Supplementary data tables}

Supplementary Table S1: Crystallographic data collection and refinement statistics.

\begin{tabular}{|c|c|c|c|}
\hline Crystal system & BCL6/WVIP & BCL6/WVIP & BCL6/WVIP \\
\hline Ligand & 2 & $8 c$ & $8 e$ \\
\hline PDB code & $70 \mathrm{KE}$ & $70 \mathrm{KF}$ & $70 \mathrm{KG}$ \\
\hline \multicolumn{4}{|l|}{ Crystal } \\
\hline Space group & $\mathrm{P} 6_{1} 22$ & $\mathrm{P} 6_{1} 22$ & $\mathrm{P} 6_{1} 22$ \\
\hline Unit cell dimensions $(\mathrm{a} / \mathrm{b} / \mathrm{c}$ in $\AA$ ) & $67.13 / 67.13 / 164.89$ & $68.49 / 68.49 / 167.48$ & $67.24 / 67.24 / 165.47$ \\
\hline Unit cell angles $\left(\alpha / \beta / \gamma\right.$ in $\left.^{\circ}\right)$ & $90 / 90 / 120$ & $90 / 90 / 120$ & $90 / 90 / 120$ \\
\hline \multicolumn{4}{|l|}{ Data collection and processing } \\
\hline Beamline & ESRF ID30A-1 & In-house Rigaku & ESRF ID30A-1 \\
\hline Wavelength $(\AA)$ & 0.9660 & 1.5419 & 0.9660 \\
\hline Integration program & XDS & DIALS & XDS \\
\hline Reduction program & AIMLESS & AIMLESS & AIMLESS \\
\hline Resolution range & $47.51-1.48$ & $33.72-1.60$ & $41.37-1.32$ \\
\hline Number of unique reflections ${ }^{a}$ & $37651(3631)$ & $30154(1500)$ & $53022(2508)$ \\
\hline Completeness $^{\mathrm{a}}$ & $100(100)$ & $99.9(99.5)$ & $99.9(97.8)$ \\
\hline Redundancy $^{\mathrm{a}}$ & $19.1(18.4)$ & $14.4(8.9)$ & $12.2(11.5)$ \\
\hline $\mathrm{R}_{\text {merge }}(\%)^{\mathrm{a}}$ & $11.0(258.5)$ & $9.6(133.7)$ & $9.8(216.9)$ \\
\hline $\mathrm{I} / \sigma(\mathrm{I})^{\mathrm{a}}$ & $17.7(1.3)$ & $16.5(1.6)$ & $13.2(1.3)$ \\
\hline $\mathrm{CC}_{1 / 2} \mathrm{a}^{\mathrm{b}}$ & $0.999(0.511)$ & $0.998(0.409)$ & $0.999(0.470)$ \\
\hline \multicolumn{4}{|l|}{ Refinement } \\
\hline Program & BUSTER & BUSTER & BUSTER \\
\hline $\mathrm{R}_{\text {work }}(\%)$ & 16.82 & 16.67 & 16.92 \\
\hline $\mathrm{R}_{\text {free }}(\%)$ & 18.66 & 17.80 & 17.95 \\
\hline Number of residues & 131 & 131 & 131 \\
\hline Number of water molecules & 188 & 204 & 195 \\
\hline Average B-factor $\left(\AA^{2}\right)$ & 28.34 & 22.32 & 22.91 \\
\hline Ramachandran favoured (\%) & 97.62 & 96.83 & 98.88 \\
\hline Ramachandran outliers (\%) & 0 & 0 & 0 \\
\hline RMSD bonds $(\AA)$ & 0.016 & 0.014 & 0.012 \\
\hline RMSD angles $\left({ }^{\circ}\right)$ & 1.520 & 1.540 & 1.483 \\
\hline
\end{tabular}

a Values in parentheses are for the highest resolution shell.

${ }^{\mathrm{b}}$ Half-dataset correlation coefficient, see: Karplus, P. A.; Diederichs, K. Linking crystallographic model and data quality. Science 2012, 336, 1030-1033. 


\begin{tabular}{|c|c|c|c|}
\hline Crystal system & BCL6/WVIP & BCL6/WVIP & BCL6/WVIP \\
\hline Ligand & 8f & 12b & $12 c$ \\
\hline PDB code & $70 \mathrm{KH}$ & $70 \mathrm{KI}$ & $70 \mathrm{KJ}$ \\
\hline \multicolumn{4}{|l|}{ Crystal } \\
\hline Space group & $\mathrm{P} 66_{1} 22$ & $\mathrm{P} 6_{1} 22$ & $\mathrm{P} 6_{1} 22$ \\
\hline Unit cell dimensions (a/b/c in $\AA$ ) & $66.45 / 66.45 / 151.20$ & $67.90 / 67.90 / 166.03$ & $67.47 / 67.47 / 165.49$ \\
\hline Unit cell angles $\left(\alpha / \beta / \gamma\right.$ in $\left.{ }^{\circ}\right)$ & $90 / 90 / 120$ & $90 / 90 / 120$ & $90 / 90 / 120$ \\
\hline \multicolumn{4}{|l|}{ Data collection and processing } \\
\hline Beamline & ESRF ID30A-1 & ESRF ID30A-1 & ESRF ID30A-1 \\
\hline Wavelength $(\AA ̊)$ & 0.9660 & 0.9660 & 0.9660 \\
\hline Integration program & XDS & XDS & XDS \\
\hline Reduction program & AIMLESS & AUTOPROC & AUTOPROC \\
\hline Resolution range & $41.40-1.52$ & $58.80-1.61$ & $58.43-1.43$ \\
\hline Number of unique reflections ${ }^{a}$ & $35422(1701)$ & 29885 (1392) & $41944(2043)$ \\
\hline Completeness $^{\mathrm{a}}$ & $100(100)$ & $98.5(93.8)$ & $100(99.3)$ \\
\hline Redundancy $^{\mathrm{a}}$ & $13.6(13.4)$ & $7.3(7.7)$ & $11.1(9.5)$ \\
\hline $\mathrm{R}_{\text {merge }}(\%)^{\mathrm{a}}$ & $19.2(268.7)$ & $10.8(80.5)$ & $9.3(109.4)$ \\
\hline $\mathrm{I} / \sigma(\mathrm{I})^{\mathrm{a}}$ & $10.9(1.2)$ & $12.3(2.5)$ & $13.7(2.2)$ \\
\hline $\mathrm{CC}_{1 / 2} \mathrm{a}, \mathrm{b}$ & $0.997(0.553)$ & $0.998(0.391)$ & $0.999(0.475)$ \\
\hline \multicolumn{4}{|l|}{ Refinement } \\
\hline Program & BUSTER & BUSTER & BUSTER \\
\hline $\mathrm{R}_{\mathrm{work}}(\%)$ & 18.07 & 16.22 & 16.54 \\
\hline $\mathrm{R}_{\text {free }}(\%)$ & 19.42 & 18.89 & 17.68 \\
\hline Number of residues & 130 & 131 & 131 \\
\hline Number of water molecules & 199 & 153 & 198 \\
\hline Average B-factor $\left(\AA^{2}\right)$ & 24.68 & 28.41 & 24.60 \\
\hline Ramachandran favoured (\%) & 97.60 & 98.41 & 98.90 \\
\hline Ramachandran outliers (\%) & 0 & 0 & 0 \\
\hline RMSD bonds $(\AA ̊)$ & 0.014 & 0.014 & 0.011 \\
\hline RMSD angles $\left({ }^{\circ}\right)$ & 1.526 & 1.551 & 1.469 \\
\hline
\end{tabular}

a Values between brackets are for the highest resolution shell.

b Half-dataset correlation coefficient, see: Karplus, P. A.; Diederichs, K. Linking crystallographic model and data quality. Science 2012, 336, 1030-1033. 


\begin{tabular}{|c|c|c|c|}
\hline Crystal system & BCL6/WVIP & BCL6/WVIP & BCL6/WVIP \\
\hline Ligand & $12 \mathrm{e}$ & $13 e$ & $13 g$ \\
\hline PDB code & $70 \mathrm{KK}$ & $70 \mathrm{KL}$ & $70 \mathrm{KM}$ \\
\hline \multicolumn{4}{|l|}{ Crystal } \\
\hline Space group & $\mathrm{P} 6_{1} 22$ & $\mathrm{P} 6_{1} 22$ & $\mathrm{P} 6_{1} 22$ \\
\hline Unit cell dimensions (a/b/c in $\AA$ ) & $67.35 / 67.35 / 164.50$ & $68.28 / 68.28 / 168.17$ & $68.49 / 68.49 / 167.48$ \\
\hline Unit cell angles $\left(\alpha / \beta / \gamma\right.$ in $\left.{ }^{\circ}\right)$ & $90 / 90 / 120$ & $90 / 90 / 120$ & $90 / 90 / 120$ \\
\hline \multicolumn{4}{|l|}{ Data collection and processing } \\
\hline Beamline & In-house Rigaku & DLS I04-1 & DLS I04-1 \\
\hline Wavelength $(\AA ̊)$ & 1.5419 & 0.9282 & 0.9282 \\
\hline Integration program & XDS & DIALS & DIALS \\
\hline Reduction program & AIMLESS & AIMLESS & AIMLESS \\
\hline Resolution range & $47.58-2.05$ & $48.37-1.25$ & $48.40-1.48$ \\
\hline Number of unique reflections ${ }^{a}$ & $14393(1070)$ & $64768(3134)$ & 39743 (1924) \\
\hline Completeness $^{\mathrm{a}}$ & $98.7(97.1)$ & $99.7(99.2)$ & $100(99.9)$ \\
\hline Redundancy $^{\mathrm{a}}$ & $10.3(6.4)$ & $12.4(12.8)$ & $12.2(11.4)$ \\
\hline $\mathrm{R}_{\text {merge }}(\%)^{\mathrm{a}}$ & $24.9(179.9)$ & $6.3(217.2)$ & $6.3(260.1)$ \\
\hline $\mathrm{I} / \sigma(\mathrm{I})^{\mathrm{a}}$ & $8.2(1.4)$ & $15.4(1.2)$ & $15.5(0.9)$ \\
\hline $\mathrm{CC}_{1 / 2} \mathrm{a}, \mathrm{b}$ & $0.982(0.364)$ & $1.000(0.503)$ & $1.000(0.472)$ \\
\hline \multicolumn{4}{|l|}{ Refinement } \\
\hline Program & BUSTER & BUSTER & BUSTER \\
\hline $\mathrm{R}_{\mathrm{work}}(\%)$ & 19.76 & 18.75 & 18.71 \\
\hline $\mathrm{R}_{\text {free }}(\%)$ & 22.37 & 19.72 & 20.56 \\
\hline Number of residues & 129 & 130 & 131 \\
\hline Number of water molecules & 132 & 197 & 194 \\
\hline Average B-factor $\left(\AA^{2}\right)$ & 21.55 & 23.60 & 34.33 \\
\hline Ramachandran favoured (\%) & 99.02 & 98.40 & 98.41 \\
\hline Ramachandran outliers (\%) & 0 & 0 & 0 \\
\hline RMSD bonds $(\AA ̊)$ & 0.012 & 0.013 & 0.015 \\
\hline RMSD angles $\left({ }^{\circ}\right)$ & 1.650 & 1.413 & 1.505 \\
\hline
\end{tabular}

${ }^{a}$ Values between brackets are for the highest resolution shell.

b Half-dataset correlation coefficient, see: Karplus, P. A.; Diederichs, K. Linking crystallographic model and data quality. Science 2012, 336, 1030-1033. 


\begin{tabular}{|c|c|}
\hline Crystal system & Flag-BCL6 \\
\hline Ligand & 25 \\
\hline PDB code & 70KD \\
\hline \multicolumn{2}{|l|}{ Crystal } \\
\hline Space group & $\mathrm{P} 6_{1} 22$ \\
\hline Unit cell dimensions $(\mathrm{a} / \mathrm{b} / \mathrm{c}$ in $\AA$ ) & $67.52 / 67.52 / 167.19$ \\
\hline Unit cell angles $\left(\alpha / \beta / \gamma\right.$ in $\left.{ }^{\circ}\right)$ & $90 / 90 / 120$ \\
\hline \multicolumn{2}{|l|}{ Data collection and processing } \\
\hline Beamline & DLS I03 \\
\hline Wavelength $(\AA)$ & 0.9762 \\
\hline Integration program & XDS \\
\hline Reduction program & AIMLESS \\
\hline Resolution range & $47.92-1.94$ \\
\hline Number of unique reflections a & 17565 (1159) \\
\hline Completeness $^{\text {a }}$ & $100(100)$ \\
\hline Redundancy $^{\mathrm{a}}$ & $12.8(12.4)$ \\
\hline $\mathrm{R}_{\text {merge }}(\%)^{\mathrm{a}}$ & $9.3(230.3)$ \\
\hline $\mathrm{I} / \sigma(\mathrm{I})^{\mathrm{a}}$ & $14.1(1.3)$ \\
\hline $\mathrm{CC}_{1 / 2}{ }^{\mathrm{a}, \mathrm{b}}$ & $0.999(0.629)$ \\
\hline \multicolumn{2}{|l|}{ Refinement } \\
\hline Program & BUSTER \\
\hline $\mathrm{R}_{\text {work }}(\%)$ & 18.09 \\
\hline $\mathrm{R}_{\text {free }}(\%)$ & 19.84 \\
\hline Number of residues & 132 \\
\hline Number of water molecules & 120 \\
\hline Average B-factor $\left(\AA^{2}\right)$ & 47.68 \\
\hline Ramachandran favoured (\%) & 99.23 \\
\hline Ramachandran outliers (\%) & 0 \\
\hline $\operatorname{RMSD}$ bonds $(\AA ̊)$ & 0.014 \\
\hline RMSD angles $\left({ }^{\circ}\right)$ & 1.636 \\
\hline
\end{tabular}

a Values between brackets are for the highest resolution shell.

b Half-dataset correlation coefficient, see: Karplus, P. A.; Diederichs, K. Linking crystallographic model and data quality. Science 2012, 336, 1030-1033. 
Supplementary Table S2: Individual values and summary statistics for TR-FRET assay.

\begin{tabular}{|c|c|c|c|c|c|c|c|c|c|c|c|c|}
\hline \multirow{2}{*}{$\begin{array}{l}\text { No } \\
1 \\
1\end{array}$} & & \multicolumn{6}{|c|}{ IC50 individual replicates, uM } & \multirow{2}{*}{$\begin{array}{c}\text { Geo } \\
\text { Mean } \\
\text { IC50 } \\
\text { uM } \\
3.27\end{array}$} & \multirow{2}{*}{$\begin{array}{r}\text { Mean } \\
\text { pIC50 }\end{array}$} & \multirow{2}{*}{$\begin{array}{c}\text { sd } \\
0.24\end{array}$} & \multirow{2}{*}{$\begin{array}{l}\text { n } \\
7\end{array}$} & \multirow{2}{*}{$\begin{array}{c}\text { LE LLE } \\
0.353 .09\end{array}$} \\
\hline & 3.32 & 4.22 & 2.23 & 1.70 & 9.38 & 3.23 & 2.47 & & & & & \\
\hline 2 & 2.28 & 4.29 & 4.07 & 1.38 & & & & 2.72 & 5.57 & 0.230 .12 & 4 & 0.352 .87 \\
\hline $8 a$ & 5.52 & 7.01 & 4.46 & & & & & 5.57 & 5.25 & 0.100 .06 & 3 & 0.313 .05 \\
\hline $8 b$ & 1.57 & 1.24 & 0.92 & 0.54 & 2.32 & & & 1.18 & 5.93 & 0.240 .11 & 5 & 0.312 .83 \\
\hline $8 c$ & 5.77 & 2.55 & 1.24 & 2.44 & 2.90 & & & 2.64 & 5.58 & 0.240 .11 & 5 & 0.283 .68 \\
\hline 8d & 2.66 & 2.56 & 1.47 & 2.10 & 2.08 & & & 2.13 & 5.67 & 0.100 .05 & 5 & 0.293 .87 \\
\hline $8 \mathbf{e}$ & 1.52 & 2.19 & & & & & & 1.82 & 5.74 & 0.110 .08 & 2 & 0.303 .54 \\
\hline $8 f$ & 1.66 & 0.68 & 1.95 & 1.13 & 1.05 & 1.91 & & 1.31 & 5.88 & 0.180 .07 & 6 & 0.343 .48 \\
\hline $11 \mathrm{a}$ & 0.89 & 0.87 & 0.81 & 0.84 & 1.12 & & & 0.90 & 6.05 & 0.060 .02 & 5 & 0.303 .05 \\
\hline 11b & 1.33 & 1.44 & 1.81 & 1.49 & & & & 1.51 & 5.82 & 0.060 .03 & 4 & 0.282 .32 \\
\hline 11c & 0.87 & 0.89 & 0.88 & & & & & 0.88 & 6.06 & 0.010 .00 & 3 & 0.293 .46 \\
\hline 11d & 0.36 & 0.27 & 0.42 & 0.35 & & & & 0.35 & 6.46 & 0.080 .04 & 4 & 0.303 .06 \\
\hline $12 a$ & 0.62 & 0.51 & 0.66 & 0.47 & 0.46 & 0.50 & $\begin{array}{lllll}0.74 & 0.48 & 0.65 & 0.49 & 0.58\end{array}$ & 0.55 & 6.26 & 0.070 .02 & 11 & 0.314 .66 \\
\hline $12 b$ & 0.24 & 0.30 & 0.22 & 0.30 & 0.28 & 0.19 & 0.26 & 0.25 & 6.60 & 0.070 .03 & 7 & 0.335 .00 \\
\hline $12 c$ & 3.39 & 2.07 & 2.27 & 3.40 & 3.90 & 2.94 & 1.54 & 2.67 & 5.57 & 0.140 .05 & 7 & 0.283 .97 \\
\hline 12d & 1.18 & 0.97 & 1.10 & & & & & 1.08 & 5.97 & 0.040 .02 & 3 & 0.283 .97 \\
\hline $12 \mathrm{e}$ & 19.94 & 22.77 & & 74.07 & 10.19 & 22.35 & & 23.81 & 4.62 & 0.310 .14 & 5 & 0.243 .42 \\
\hline $13 a$ & 1.19 & 0.70 & 0.72 & 0.75 & 0.97 & 0.55 & 0.750 .88 & 0.79 & 6.10 & 0.100 .04 & 8 & 0.294 .30 \\
\hline $13 b$ & 1.95 & 1.10 & 0.97 & 0.79 & 0.79 & & & 1.05 & 5.98 & 0.160 .07 & 5 & 0.283 .88 \\
\hline $13 c$ & 0.69 & 1.07 & 0.68 & 1.18 & 0.84 & & & 0.87 & 6.06 & 0.110 .05 & 5 & 0.274 .56 \\
\hline 13d & 0.12 & 0.40 & 0.16 & & & & & 0.20 & 6.70 & 0.270 .15 & 3 & 0.305 .20 \\
\hline $13 e$ & 0.12 & 0.09 & 0.19 & 0.16 & 0.12 & 0.17 & 0.110 .150 .16 & 0.14 & 6.86 & 0.110 .04 & 9 & 0.314 .86 \\
\hline $13 f$ & 0.07 & 0.09 & 0.09 & & & & & 0.08 & 7.08 & 0.060 .03 & 3 & 0.325 .08 \\
\hline $17 a$ & 0.41 & 0.23 & 0.79 & & & & & 0.42 & 6.38 & 0.270 .16 & 3 & 0.263 .48 \\
\hline $17 b$ & 0.25 & 0.21 & 0.64 & & & & & 0.32 & 6.49 & 0.260 .15 & 3 & 0.263 .19 \\
\hline $24 a$ & 0.06 & 0.07 & 0.09 & & & & & 0.07 & 7.14 & 0.090 .05 & 3 & 0.314 .54 \\
\hline $24 b$ & 0.05 & 0.05 & 0.06 & & & & & 0.05 & 7.27 & 0.030 .02 & 3 & 0.304 .27 \\
\hline $13 g$ & 0.05 & 0.08 & 0.05 & 0.02 & 0.04 & 0.06 & & 0.05 & 7.33 & 0.200 .08 & 6 & 0.325 .33 \\
\hline 25 & 0.04 & 0.02 & 0.03 & 0.03 & 0.02 & & & 0.03 & 7.58 & 0.160 .07 & 5 & 0.304 .58 \\
\hline
\end{tabular}


Supplementary Table S3: Individual values and summary statistics for NanoBRET assay.

\begin{tabular}{|c|c|c|c|c|c|c|c|c|c|}
\hline compound & IC5 & indiv & $\begin{array}{c}\text { idual } \\
\text { uM }\end{array}$ & eplic & tes, & & $\begin{array}{c}\text { Geo Mean IC50 } \\
\text { uM }\end{array}$ & $\begin{array}{l}\text { pIC50 } \\
\text { mean }\end{array}$ & sd $\operatorname{sem} n$ \\
\hline 1 & 36.2 & 41.5 & & & & & 38.75 & 4.41 & 0.040 .032 \\
\hline $13 e$ & 1.12 & 1.02 & 1.17 & 1.1 & 1.59 & 1.680 .961 .121 .31 & 1.21 & 5.92 & 0.080 .039 \\
\hline $13 f$ & 0.87 & 2.13 & 1.79 & & & & 1.49 & 5.83 & 0.210 .123 \\
\hline $17 a$ & 6.82 & 5.7 & 2.81 & & & & 4.78 & 5.32 & 0.200 .123 \\
\hline $17 b$ & 2.07 & 4.64 & 0.96 & & & & 2.10 & 5.68 & 0.340 .203 \\
\hline $24 a$ & 1.08 & 1.08 & & & & & 1.08 & 5.97 & 0.000 .002 \\
\hline $24 b$ & 0.96 & 1.52 & 0.96 & & & & 1.12 & 5.95 & 0.120 .073 \\
\hline $13 g$ & 0.3 & 0.67 & 0.5 & & & & 0.47 & 6.33 & 0.180 .103 \\
\hline 25 & 0.72 & 0.51 & 0.56 & 0.51 & & & 0.57 & 6.25 & 0.070 .044 \\
\hline
\end{tabular}

Supplementary Table S4: SPR sensorgrams and Langmuir curves for 25

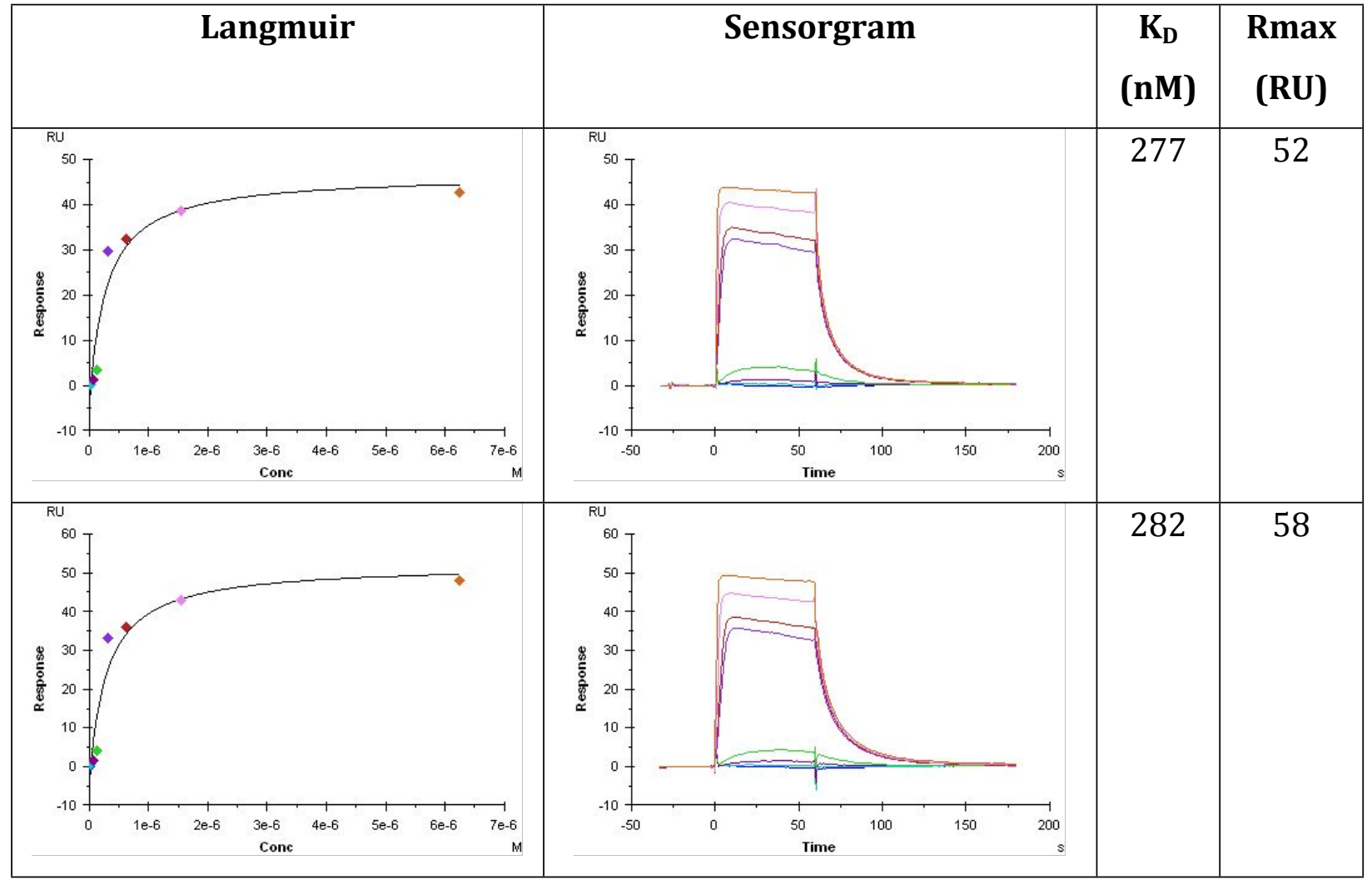




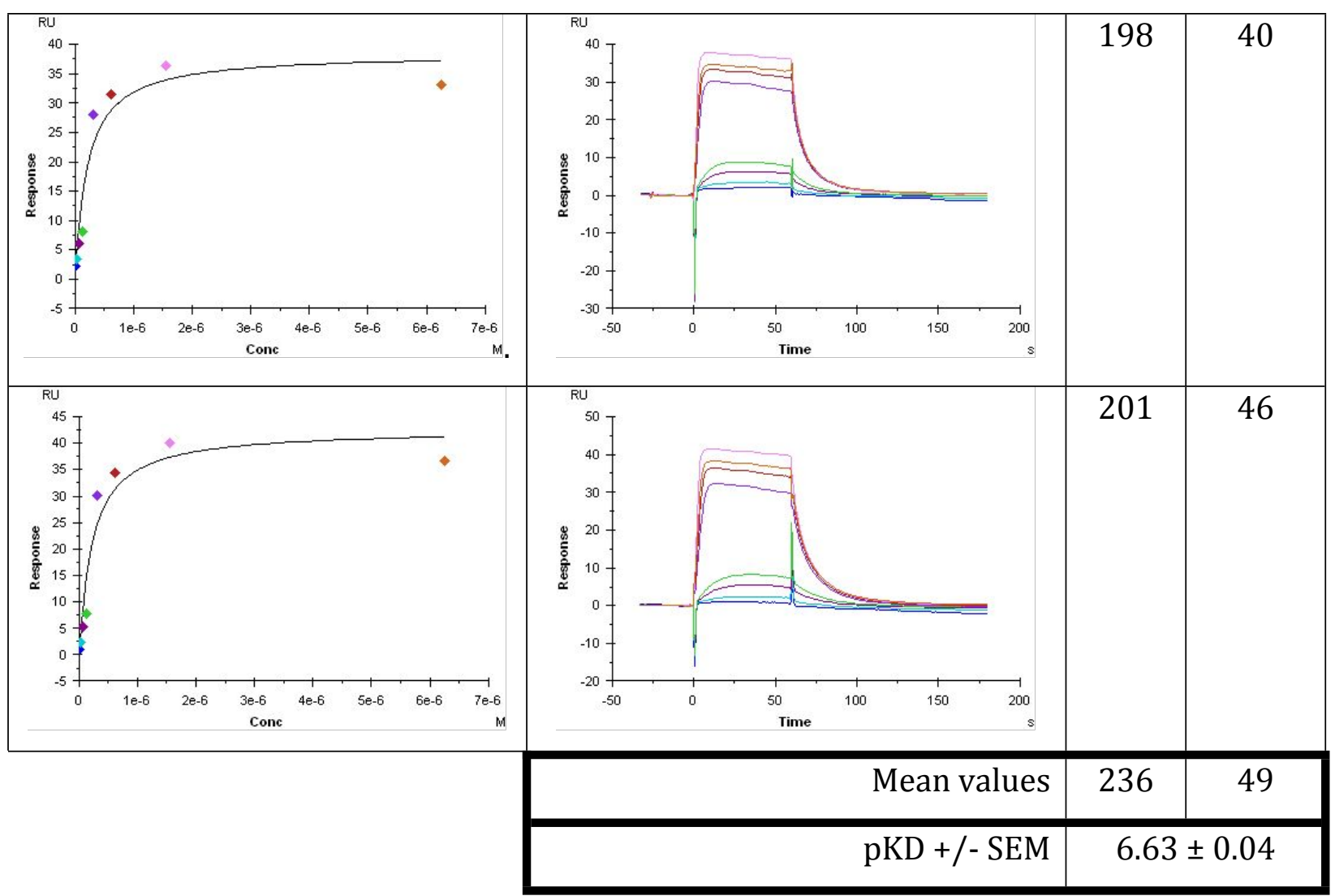

Supplementary Table S5: Data (individual replicates) from pharmacokinetic study of 25.

\begin{tabular}{|c|c|c|c|c|c|c|c|c|c|c|c|c|}
\hline \multirow[t]{2}{*}{ Route } & \multirow{2}{*}{$\begin{array}{c}\text { Dose } \\
(\mathrm{mg} / \mathrm{kg})\end{array}$} & \multirow[t]{2}{*}{ Animal } & \multirow{2}{*}{$\begin{array}{c}\text { Animal Wt } \\
\text { (g) }\end{array}$} & \multirow{2}{*}{$\begin{array}{c}\operatorname{Tmax} \\
\text { (h) }\end{array}$} & \multirow{2}{*}{$\begin{array}{c}\text { Cmax } \\
\text { (nmol/L) }\end{array}$} & \multirow{2}{*}{$\begin{array}{c}\text { AUClast } \\
\left(h^{*} \text { nmol/L) }\right.\end{array}$} & \multirow{2}{*}{$\begin{array}{c}\text { AUCINF } \\
\left(h^{*} \text { nmol/L) }\right.\end{array}$} & \multirow{2}{*}{\begin{tabular}{|c|}
$\mathrm{CL}$ \\
$(\mathrm{ml} / \mathrm{min} / \mathrm{kg})$
\end{tabular}} & \multirow{2}{*}{$\begin{array}{c}\text { HL_Lambda_z } \\
\text { (h) }\end{array}$} & \multirow{2}{*}{$\begin{array}{l}\text { Vss } \\
\text { (L/kg) }\end{array}$} & \multicolumn{2}{|c|}{$F^{*}$} \\
\hline & & & & & & & & & & & AUClast & AUCINF \\
\hline \multirow{3}{*}{ IV } & \multirow{3}{*}{1} & 2 & 18.6 & \begin{tabular}{|l|}
0.08 \\
\end{tabular} & 521 & 1275 & 1376 & 24.9 & 7.99 & 9.43 & & \\
\hline & & 3 & 18.9 & 0.08 & 471 & 1395 & 1450 & 23.7 & 5.93 & 6.96 & - & - \\
\hline & & 4 & 19.4 & 0.08 & 443 & 1344 & 1416 & 24.2 & 6.83 & 7.81 & & \\
\hline \multirow{3}{*}{ PO } & \multirow{3}{*}{5} & 6 & 18.6 & 2 & 347 & 1352 & 1435 & 24.5 & 1.33 & \multirow{3}{*}{ - } & \multirow{3}{*}{0.29} & \multirow{3}{*}{0.30} \\
\hline & & 7 & 20.0 & 2 & 382 & 1534 & 1848 & 19.0 & 2.12 & & & \\
\hline & & 8 & 19.9 & 1 & 427 & 1233 & 1279 & 27.5 & 1.14 & & & \\
\hline
\end{tabular}

* assuming linear $P K$, calculated from AUC6h 


\section{Supplementary figures}

Supplementary Figure S1: Alternative binding conformations of $8 \boldsymbol{e}$ shown by X-ray

A

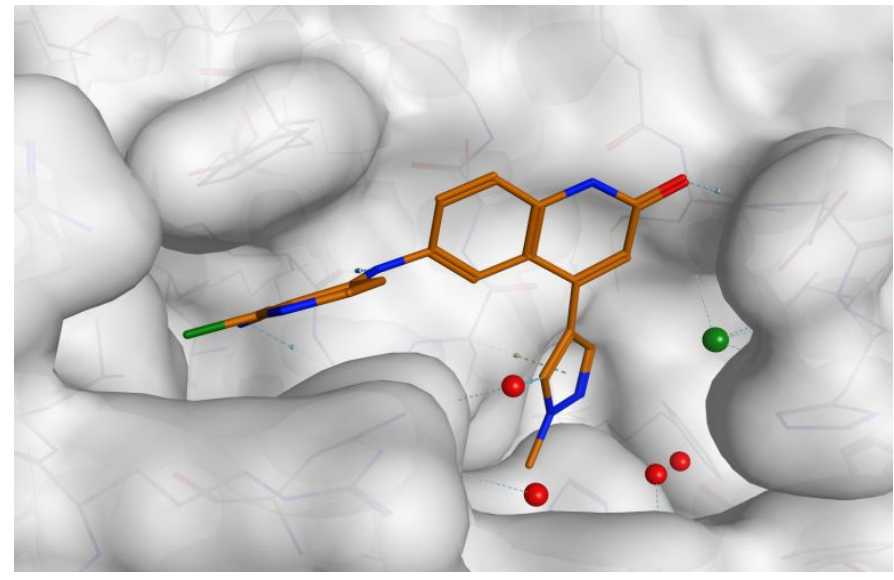

$\mathrm{B}$

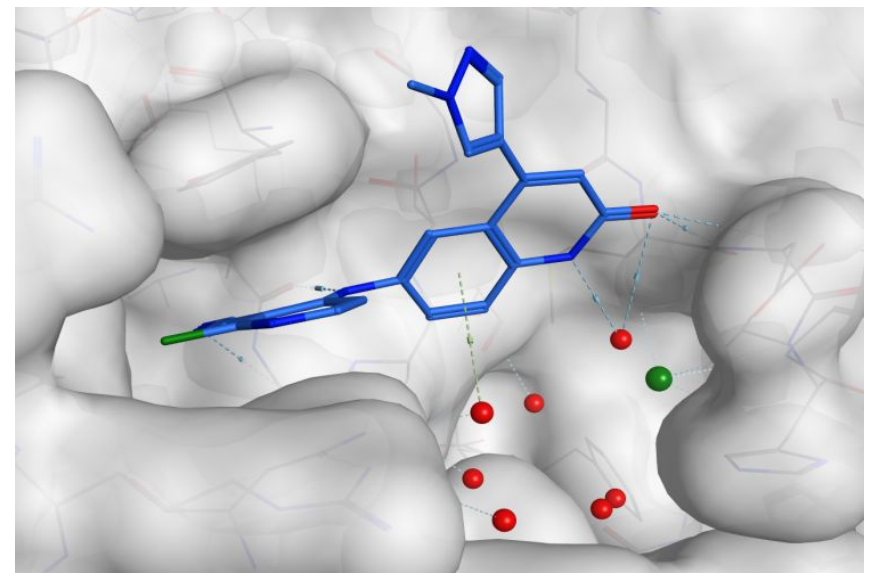

$X$-ray structure of-8e shown in its two alternate conformations, pocket-facing (A) and solvent-facing (B), each showing associated water molecules in extended pocket. PDB: 7OKG

Supplementary Figure S2: X-ray structure of $12 \boldsymbol{e}$ bound to the BTB domain of BCL6.

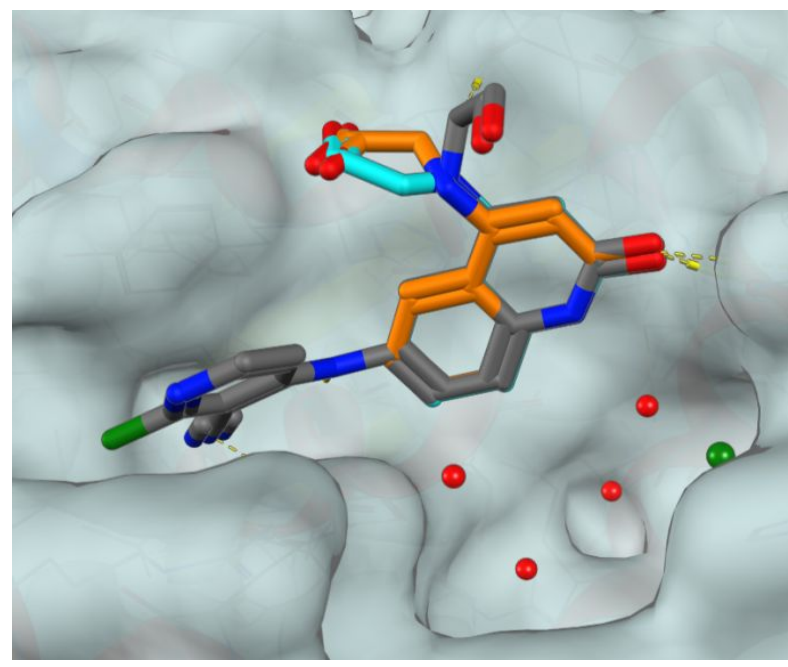

$X$-ray structure of-12e showing ligand bound in the 'solvent-facing' orientation, with associated water molecules in extended pocket. Atoms from the pendant amide group which were poorly stabilised are omitted here for clarity. Three different conformations of the pendant amide group are observed, shown in grey, orange and cyan. PDB: 7OKK 
Supplementary Figure S3: Alternative view of X-ray structures of $\mathbf{8 f}$ showing key measurements.

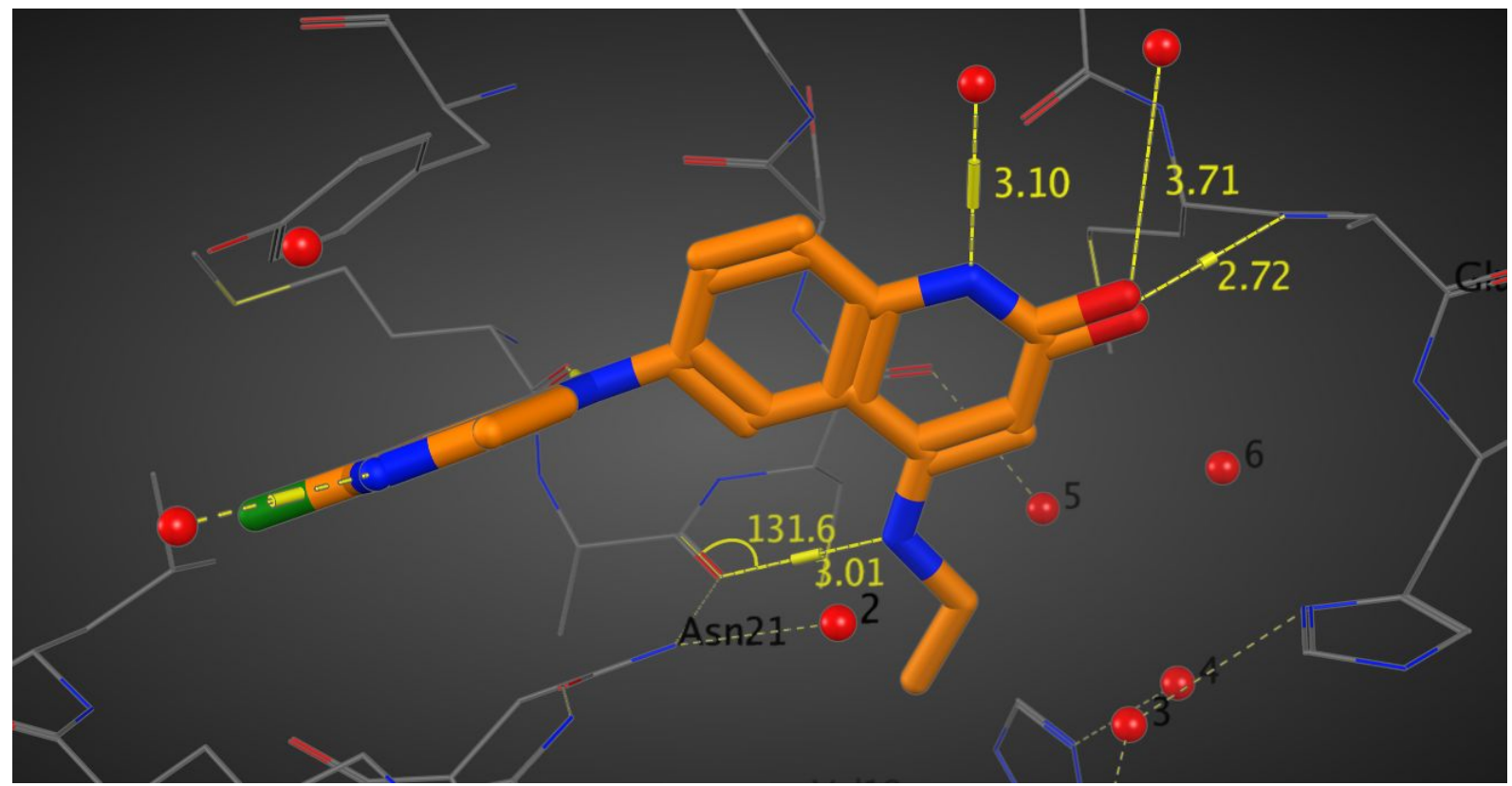

Compound 8f (PDB: 70KH)

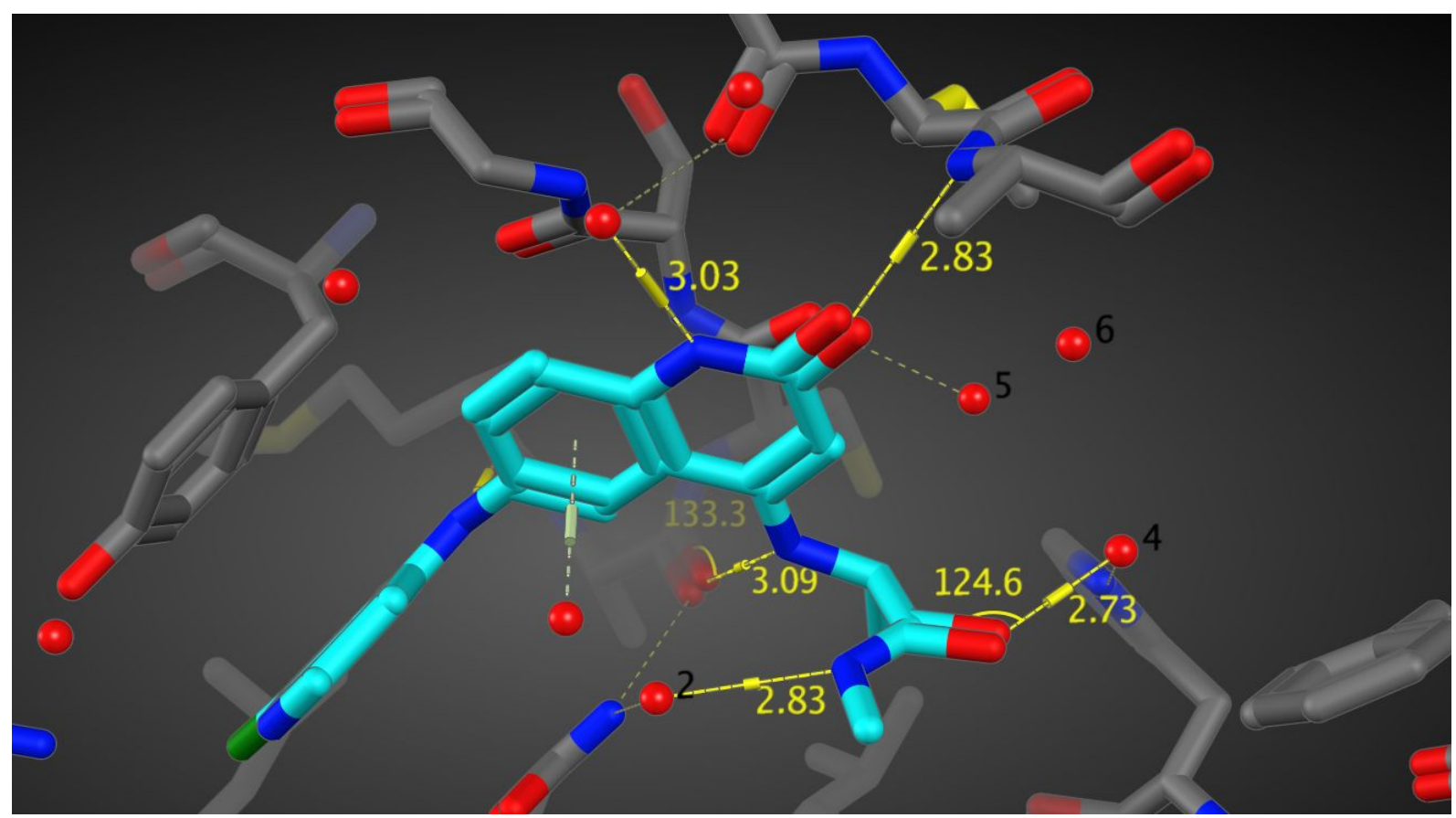

Compound 12b (PDB: 70KI) 


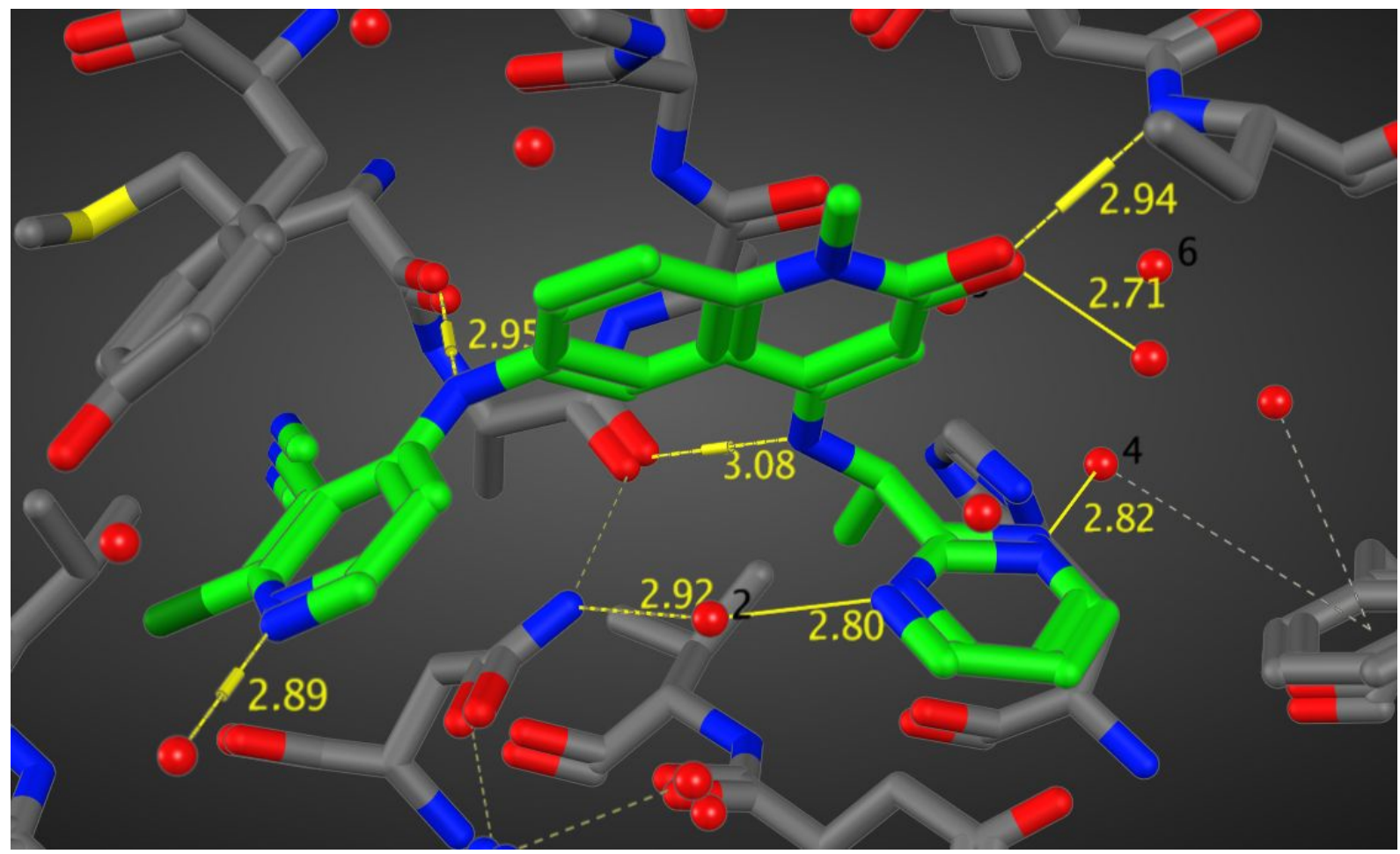

Compound 13e (PDB: 70KL)

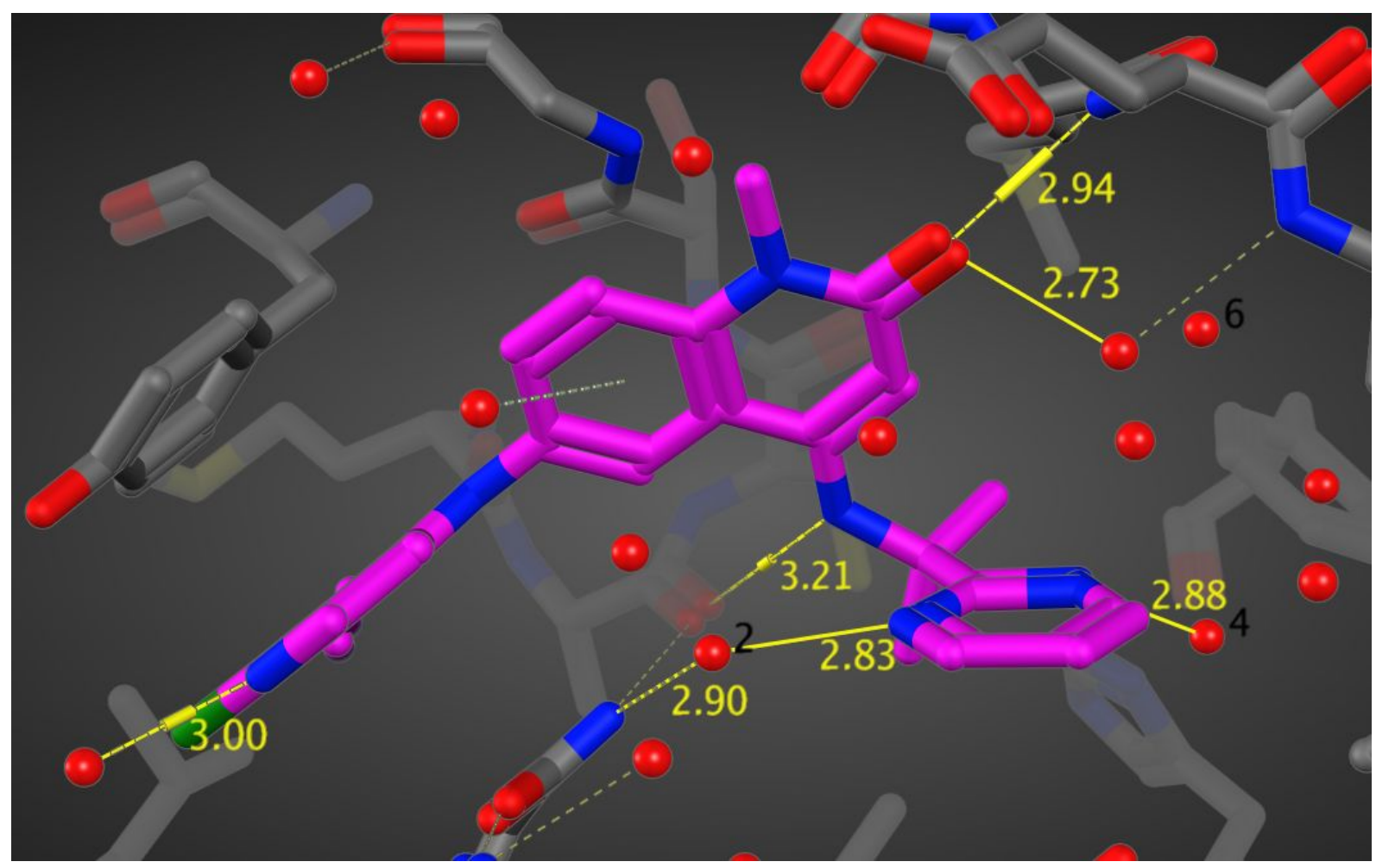

Compound 13g (PDB: 70KG) 


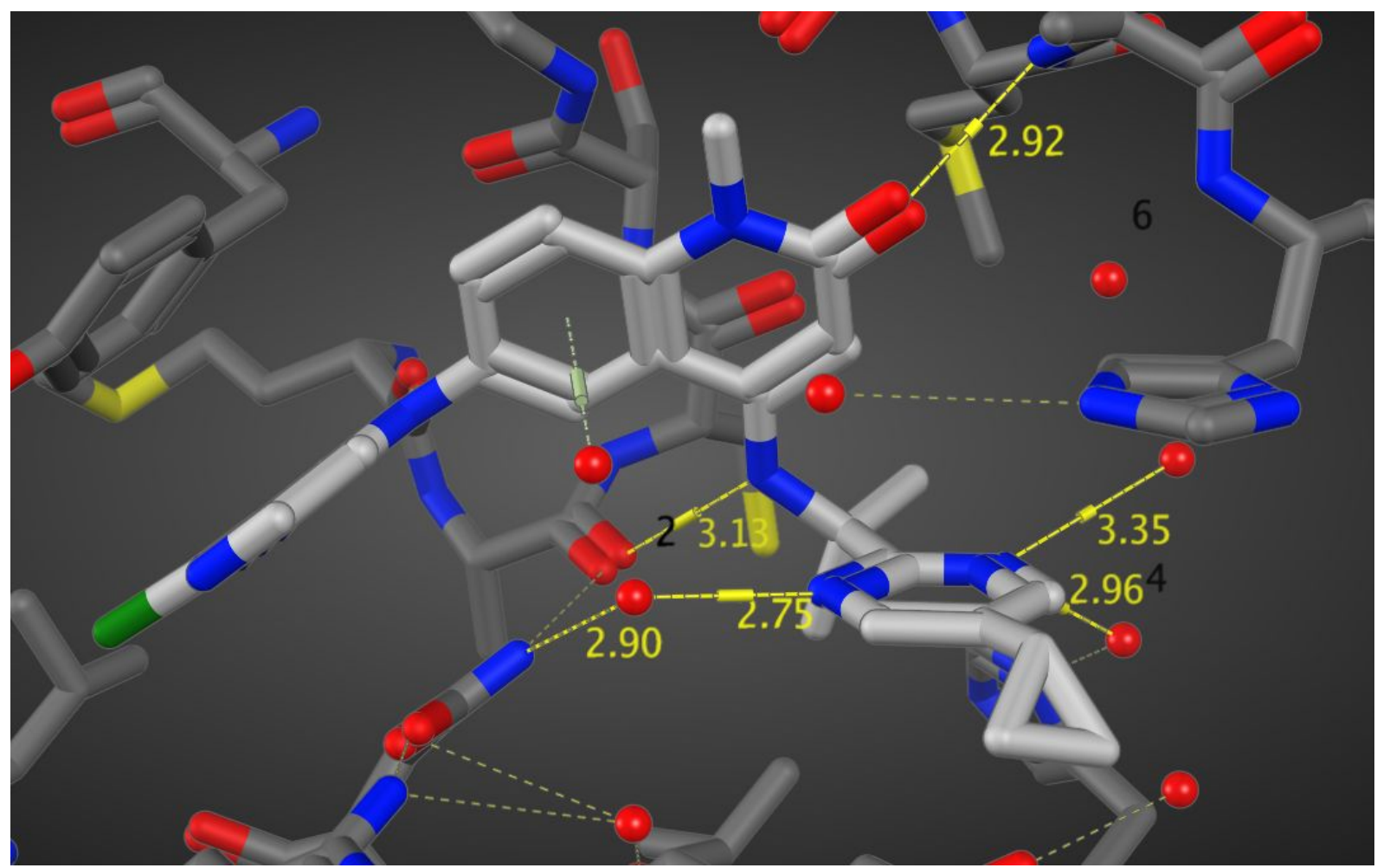

Compound 25 (PDB: 70KD) 
Supplementary Figure S4: Concentration:time curves from PK study with 25

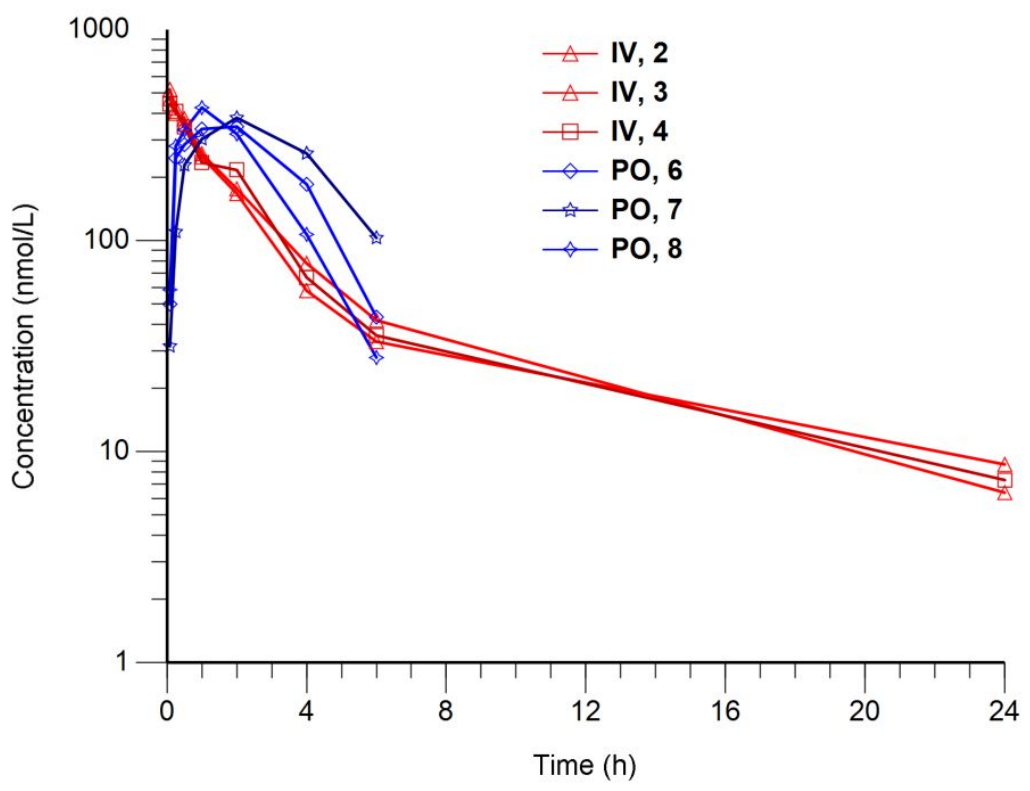


Supplementary Figure S5: Curves from 14-day cell viability assays with compound 25
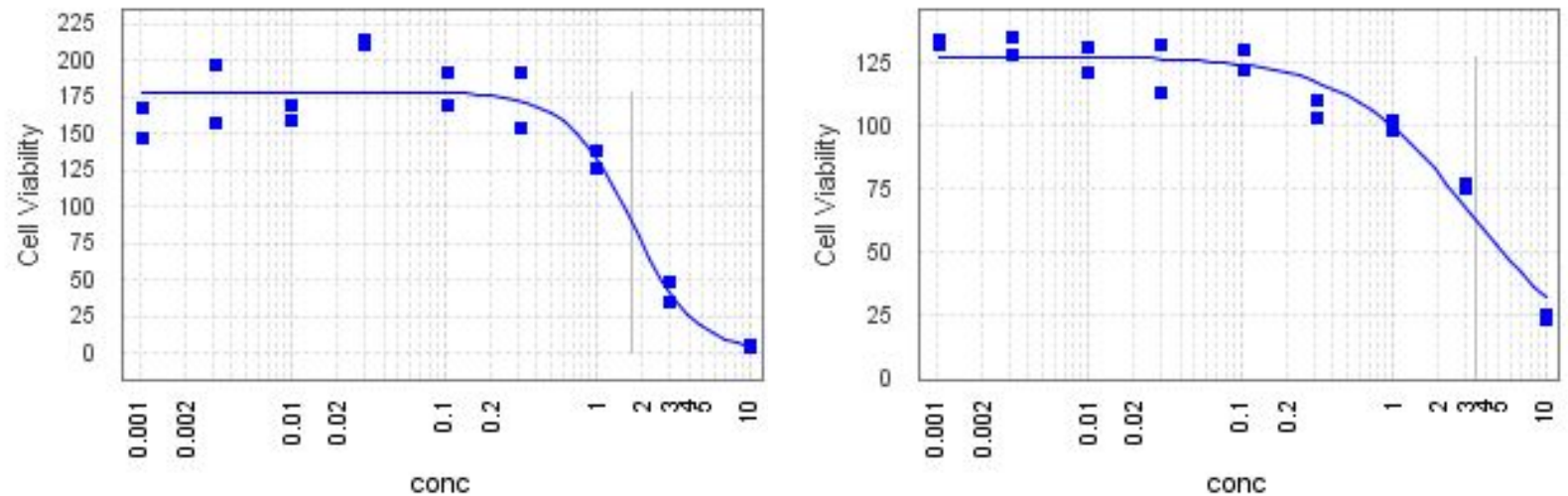

OCI-Ly1, GI50 = $1.68 \mu \mathrm{M}$

SU-DHL-4, GI50 = $3.45 \mu \mathrm{M}$

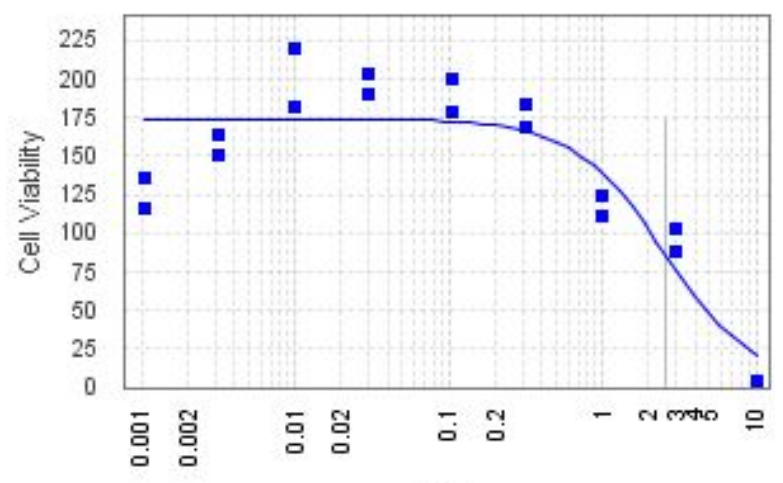

\section{SU-DHL-6, GI50 = $2.55 \mu \mathrm{M}$}

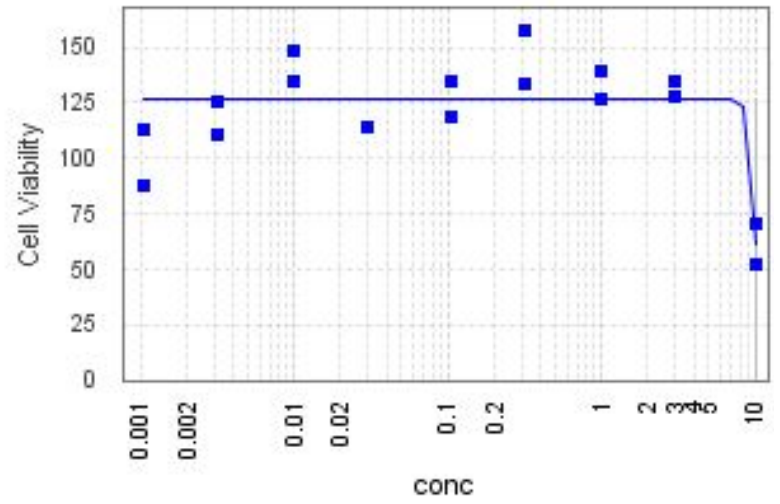

OCI-Ly3, GI50 > $10 \mu \mathrm{M}$

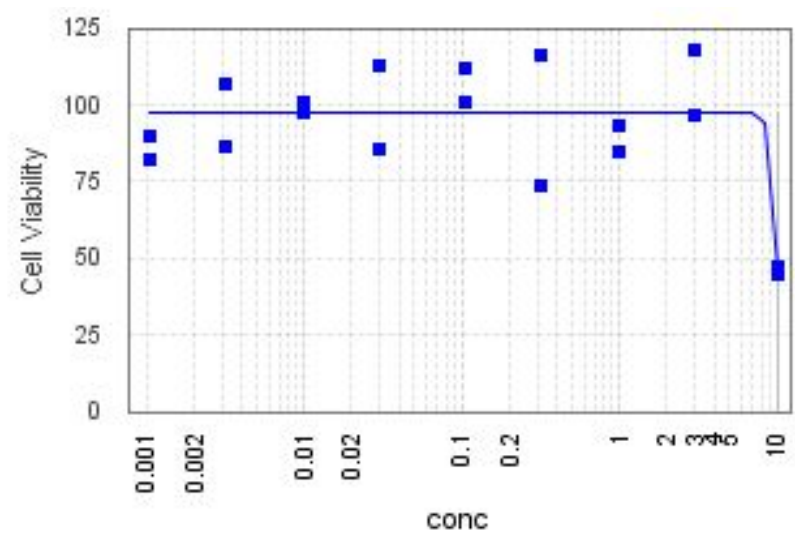

MM.1S, GI50 > $10 \mu \mathrm{M}$ 


\section{Supplementary analytical data}

\subsection{LCMS traces for key compounds}

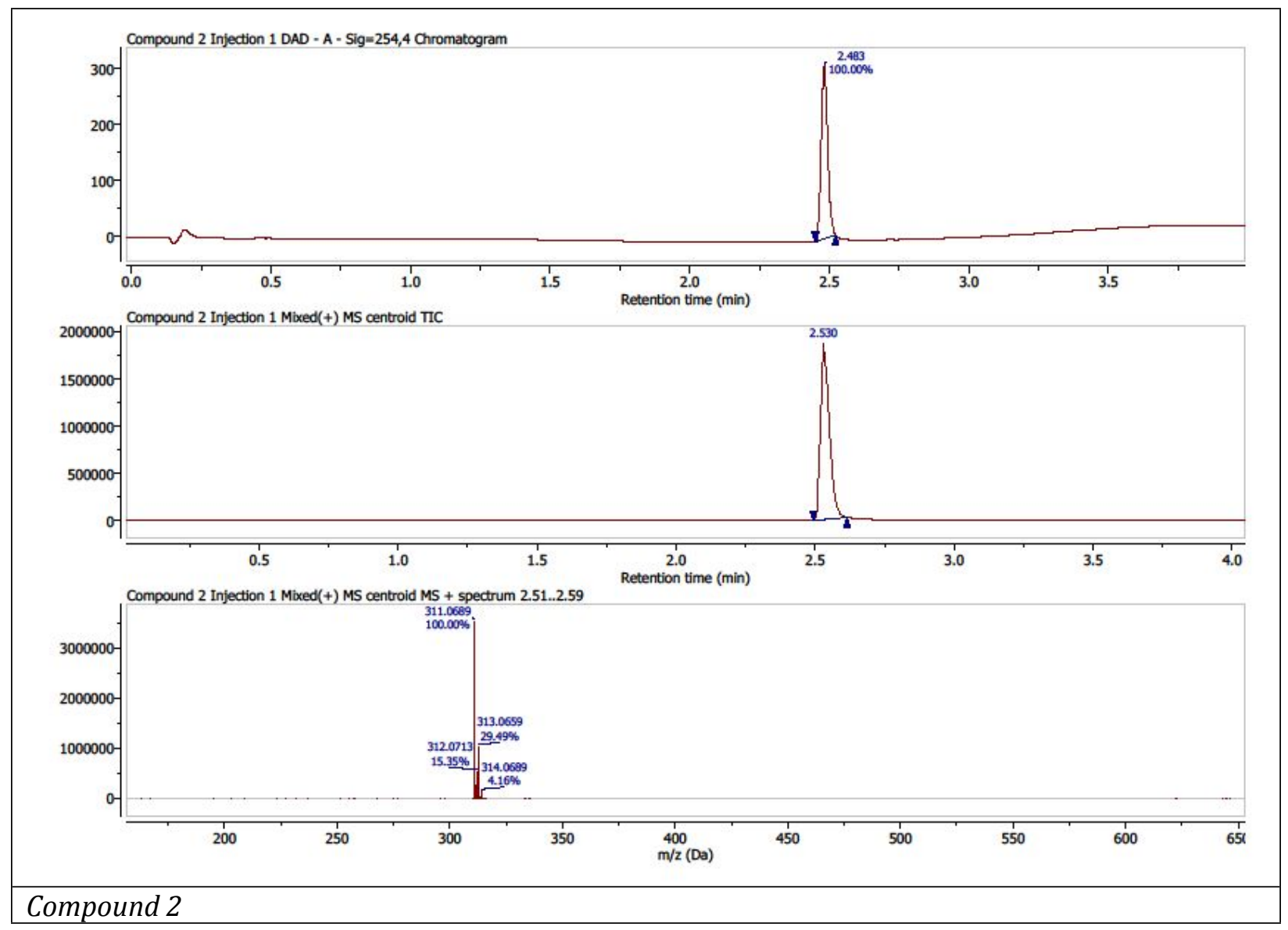




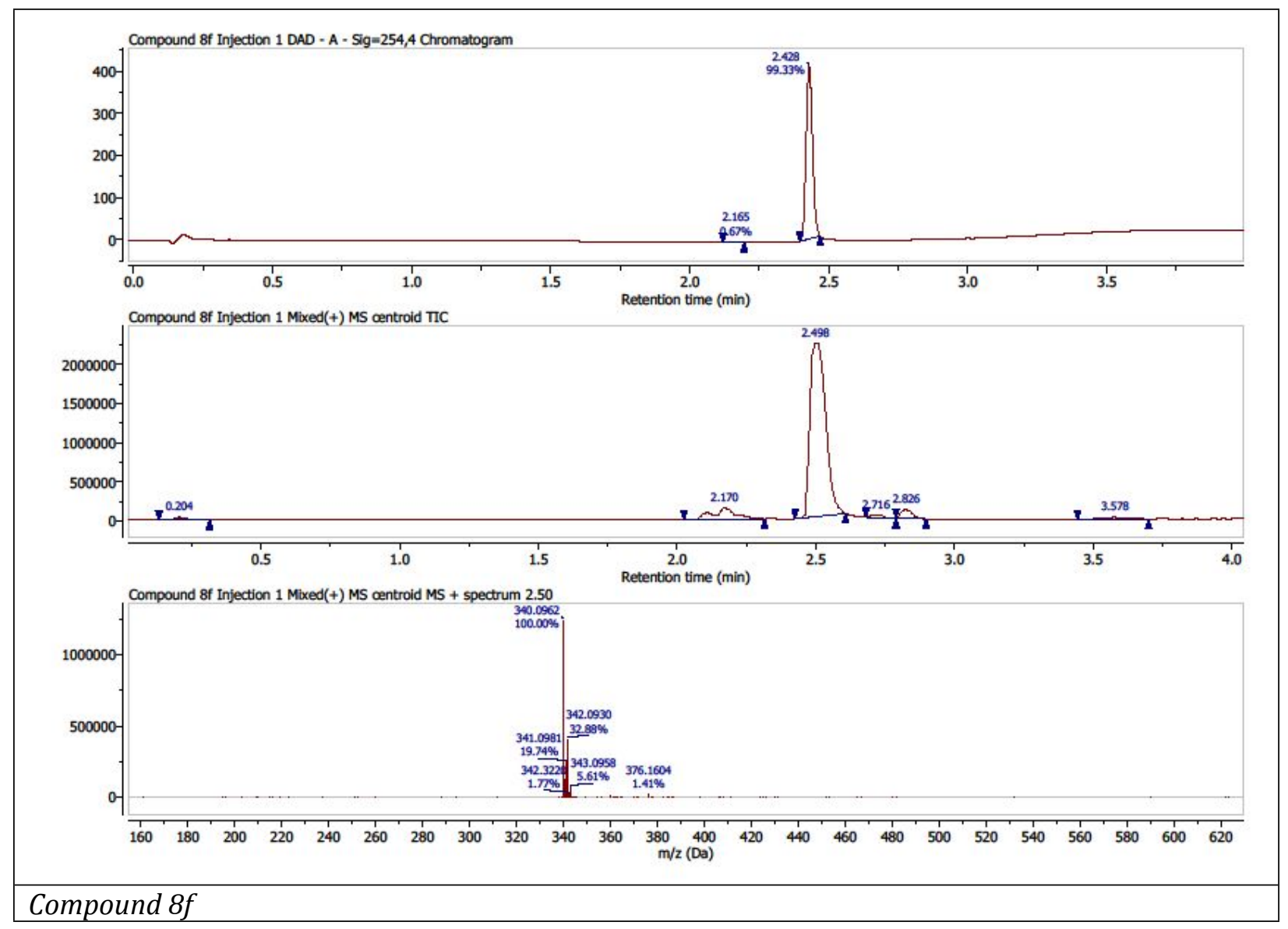




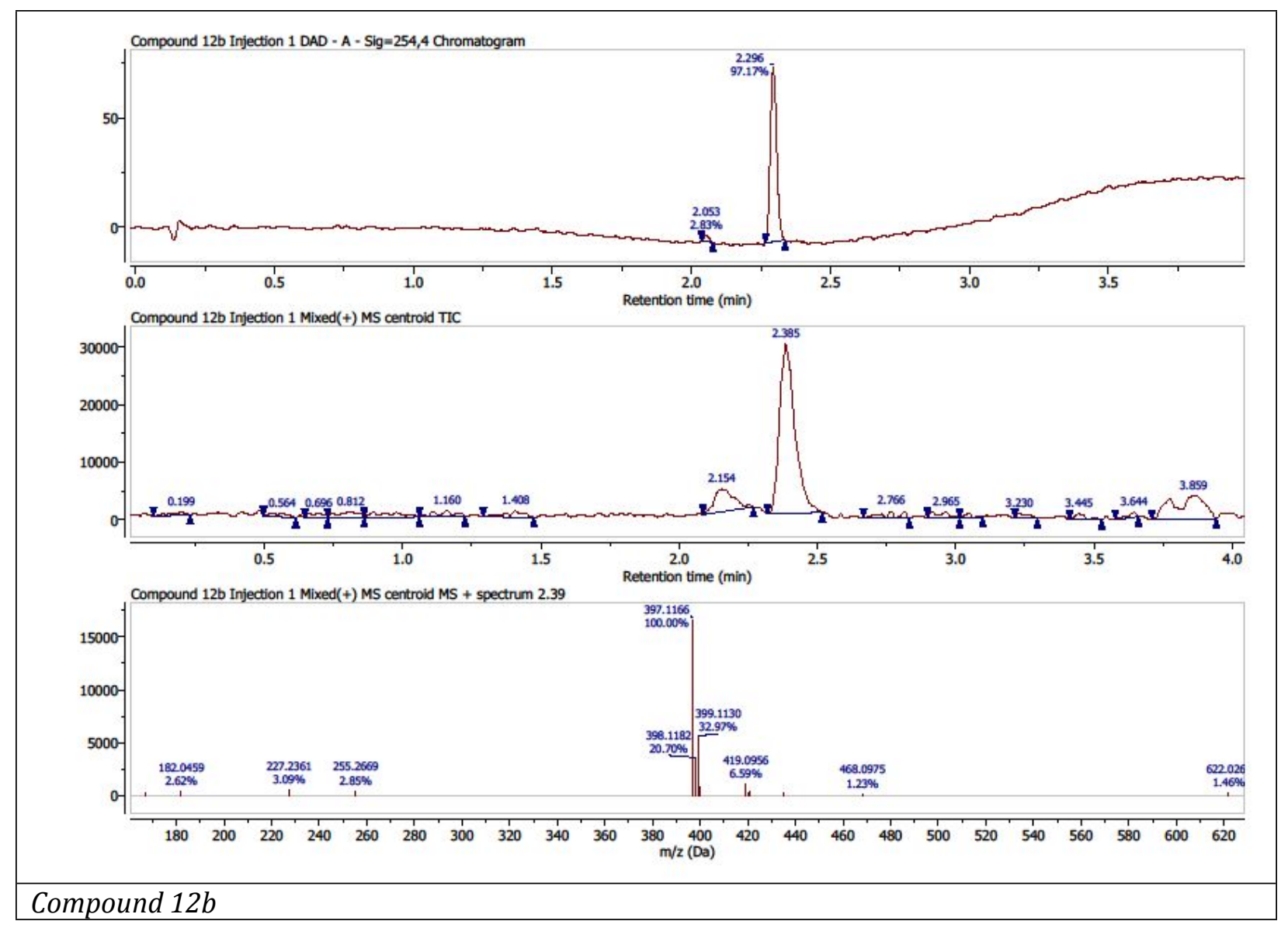




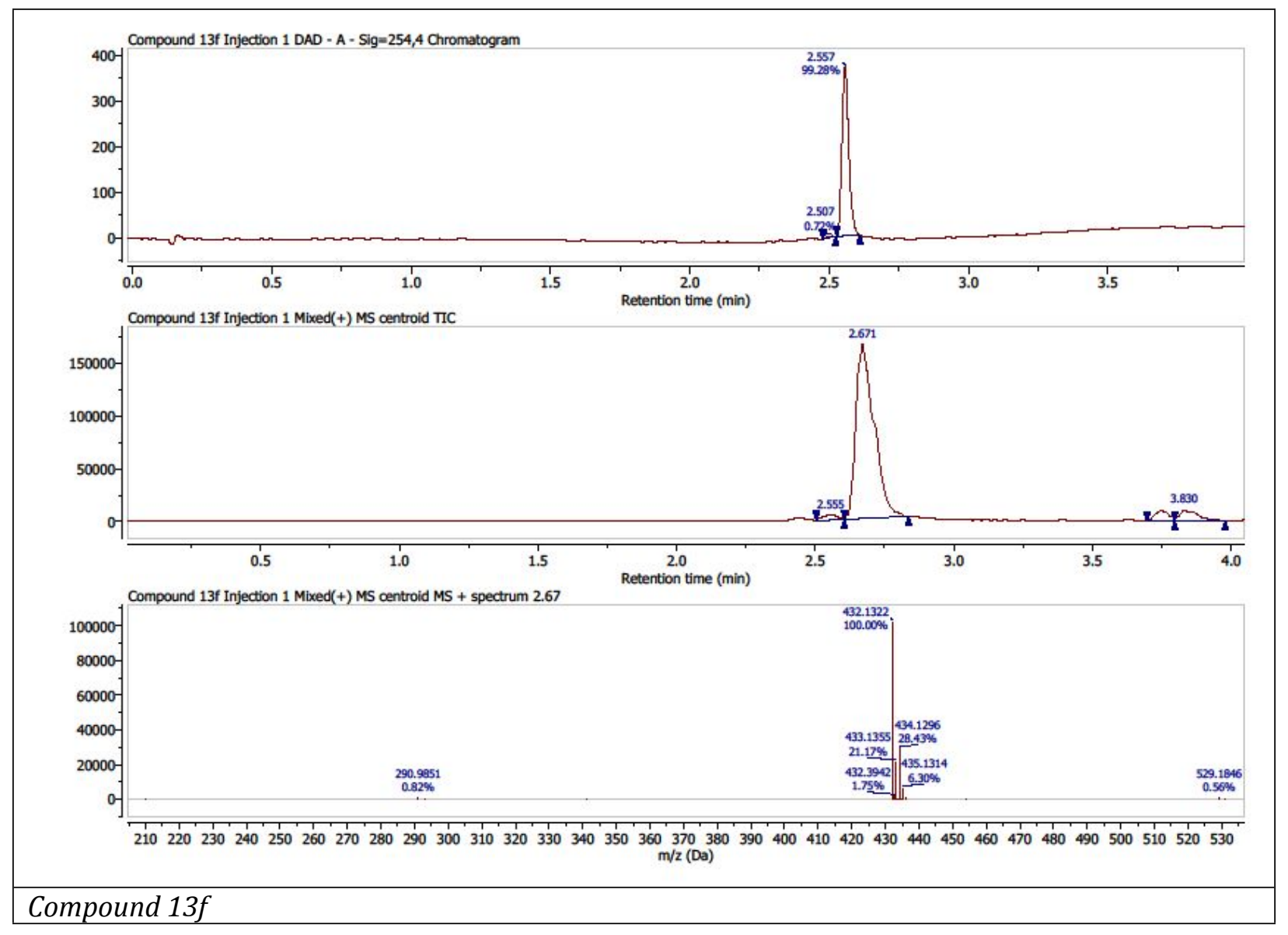




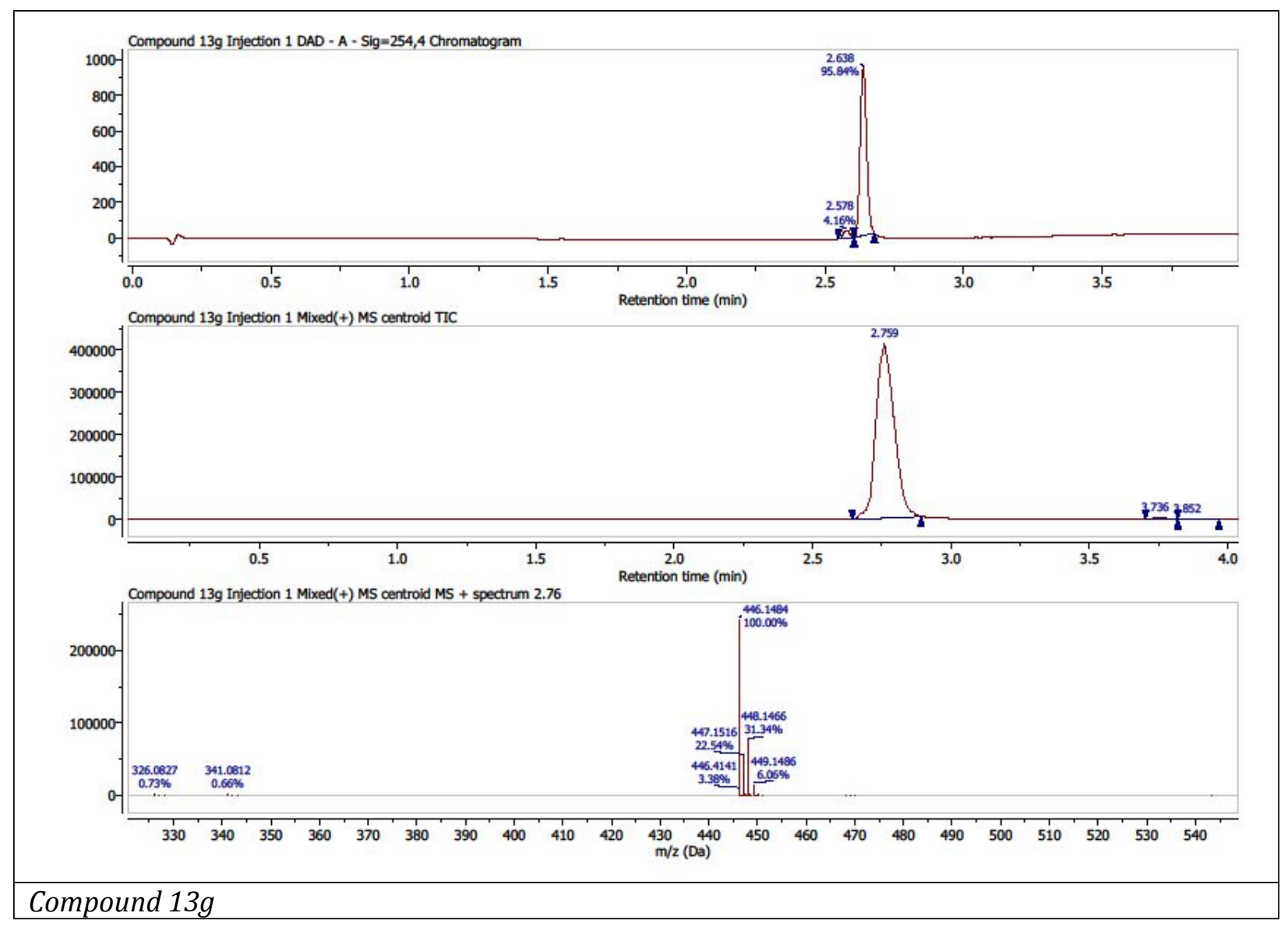




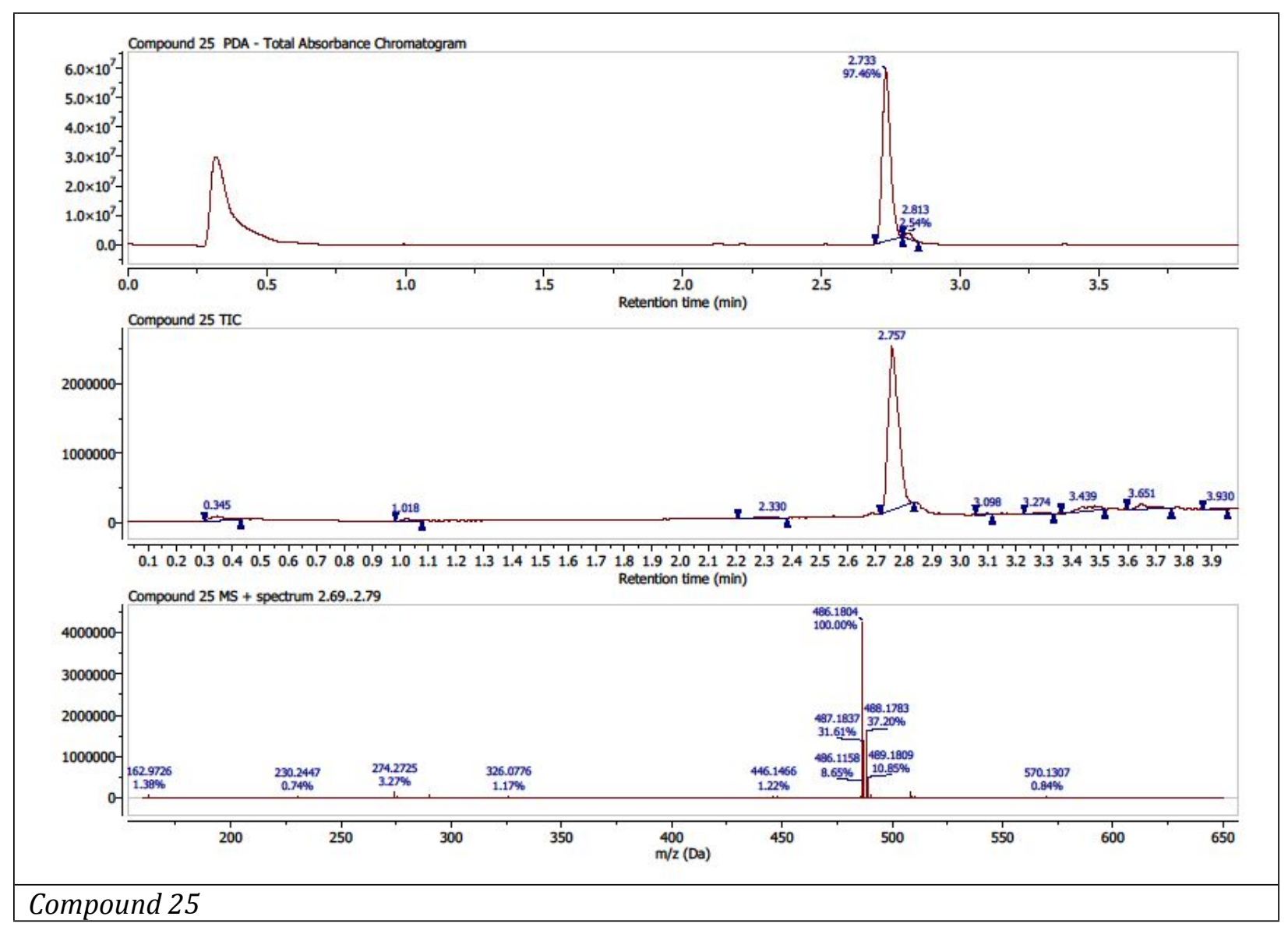




\section{References for supplementary information}

1. Kabsch, W., XDS. Acta Crystallographica Section D 2010, 66 (2), 125-132.

2. Winter, G.; Waterman, D. G.; Parkhurst, J. M.; Brewster, A. S.; Gildea, R. J.; Gerstel, M.; Fuentes-Montero, L.; Vollmar, M.; Michels-Clark, T.; Young, I. D.; Sauter, N. K.; Evans, G., DIALS: implementation and evaluation of a new integration package. Acta Crystallographica Section D 2018, 74 (2), 85-97.

3. Evans, P., Scaling and assessment of data quality. Acta Crystallographica Section D 2006, 62 (1), 72-82.

4. Vonrhein, C.; Flensburg, C.; Keller, P.; Sharff, A.; Smart, O.; Paciorek, W.; Womack, T.; Bricogne, G., Data processing and analysis with the autoPROC toolbox. Acta Crystallographica Section D 2011, 67 (4), 293-302.

5. McCoy, A. J.; Grosse-Kunstleve, R. W.; Adams, P. D.; Winn, M. D.; Storoni, L. C.; Read, R. J., Phaser crystallographic software. Journal of Applied Crystallography 2007, 40 (4), 658674.

6. Winn, M. D.; Ballard, C. C.; Cowtan, K. D.; Dodson, E. J.; Emsley, P.; Evans, P. R.; Keegan, R. M.; Krissinel, E. B.; Leslie, A. G. W.; McCoy, A.; McNicholas, S. J.; Murshudov, G. N.; Pannu, N. S.; Potterton, E. A.; Powell, H. R.; Read, R. J.; Vagin, A.; Wilson, K. S., Overview of the CCP4 suite and current developments. Acta Crystallographica Section D 2011, 67 (4), 235-242.

7. Ghetu, A. F.; Corcoran, C. M.; Cerchietti, L.; Bardwell, V. J.; Melnick, A.; Privé, G. G., Structure of a BCOR Corepressor Peptide in Complex with the BCL6 BTB Domain Dimer. Molecular Cell 2008, 29 (3), 384-391.

8. Emsley, P.; Cowtan, K., Coot: model-building tools for molecular graphics. Acta Crystallographica Section D 2004, 60 (12 Part 1), 2126-2132.

9. G. Bricogne, E. B., M. Brandl, C. Flensburg, P. Keller, W. Paciorek, P. Roversi,; A. Sharff, O. S. S., C. Vonrhein, T.O. Womack, BUSTER, Version 2.10.2, Global Phasing Ltd., Cambridge, United Kingdom 2015.

10. O.S. Smart, T. O. W., A. Sharff, C. Flensburg, P. Keller, W. Paciorek,; C. Vonrhein, G. B., Grade, Version 1.2.9, Global Phasing Ltd., Cambridge, United Kingdom, 2014.

11. Bruno, I. J.; Cole, J. C.; Lommerse, J. P. M.; Rowland, R. S.; Taylor, R.; Verdonk, M. L., IsoStar: A library of information about nonbonded interactions. Journal of Computer-Aided Molecular Design 1997, 11 (6), 525-537. 
12. Chen, V. B.; Arendall, W. B., III; Headd, J. J.; Keedy, D. A.; Immormino, R. M.; Kapral, G. J.; Murray, L. W.; Richardson, J. S.; Richardson, D. C., MolProbity: all-atom structure validation for macromolecular crystallography. Acta Crystallographica Section D 2010, 66 (1), 12-21. 13. Davis, I. W.; Leaver-Fay, A.; Chen, V. B.; Block, J. N.; Kapral, G. J.; Wang, X.; Murray, L. W.; Arendall, W. B., III; Snoeyink, J.; Richardson, J. S.; Richardson, D. C., MolProbity: all-atom contacts and structure validation for proteins and nucleic acids. Nucleic Acids Research 2007, 35 (suppl_2), W375-W383.

14. Wider, G.; Dreier, L., Measuring Protein Concentrations by NMR Spectroscopy. Journal of the American Chemical Society 2006, 128 (8), 2571-2576.

15. Lin, M.; Tesconi, M.; Tischler, M., Use of $1 \mathrm{H}$ NMR to facilitate solubility measurement for drug discovery compounds. International Journal of Pharmaceutics 2009, 369 (1), 47-52. 16. Saal, C.; Petereit, A. C., Optimizing solubility: Kinetic versus thermodynamic solubility temptations and risks. European Journal of Pharmaceutical Sciences 2012, 47 (3), 589-595.

17. Workman, P.; Aboagye, E. O.; Balkwill, F.; Balmain, A.; Bruder, G.; Chaplin, D. J.; Double, J. A.; Everitt, J.; Farningham, D. A. H.; Glennie, M. J.; Kelland, L. R.; Robinson, V.; Stratford, I. J.; Tozer, G. M.; Watson, S.; Wedge, S. R.; Eccles, S. A.; An ad hoc committee of the National Cancer Research, I., Guidelines for the welfare and use of animals in cancer research. British Journal of Cancer 2010, 102 (11), 1555-1577. 